\title{
Ascl1 Converts Dorsal Midbrain Astrocytes into Functional Neurons In Vivo
}

\author{
Yueguang Liu, ${ }^{1 \star}$ Qinglong Miao, ${ }^{1,2,3 *}$ Jiacheng Yuan, ${ }^{1}$ Su'e Han, ${ }^{1,3}$ Panpan Zhang, ${ }^{1,3}$ Sanlan Li, ${ }^{1,3}$ Zhiping Rao, ${ }^{1,3}$ \\ Wenlong Zhao, ${ }^{1,3}$ Qian Ye, ${ }^{2}$ Junlan Geng, ${ }^{1}$ Xiaohui Zhang, ${ }^{2 \dagger}$ and Leping Cheng ${ }^{1,3{ }^{\dagger}}$ \\ ${ }^{1}$ Institute of Neuroscience and State Key Laboratory of Neuroscience, Shanghai Institutes for Biological Sciences, Chinese Academy of Sciences, Shanghai \\ 200031, China, ${ }^{2}$ State Key Laboratory of Cognitive Neuroscience and Learning, and IDG/McGovern Institute for Brain Research, Beijing Normal University, \\ Beijing 100875, China, and ${ }^{3}$ University of Chinese Academy of Sciences, Shanghai 200031, China
}

In vivo induction of non-neuronal cells into neurons by transcription factors offers potential therapeutic approaches for neural regeneration. Although generation of induced neuronal (iN) cells in vitro and in vivo has been reported, whether iN cells can be fully integrated into existing circuits remains unclear. Here we show that expression of achaete-scute complex homolog-like 1 (Ascl1) alone is sufficient to convert dorsal midbrain astrocytes of mice into functional iN cells in vitro and in vivo. Specific expression of Ascl1 in astrocytes by infection with GFAP-adeno-associated virus (AAV) vector converts astrocytes in dorsal midbrain, striatum, and somatosensory cortex of postnatal and adult mice into functional neurons in vivo. These iN cells mature progressively, exhibiting neuronal morphology and markers, action potentials, and synaptic inputs from and output to existing neurons. Thus, a single transcription factor, Ascl1, is sufficient to convert brain astrocytes into functional neurons, and GFAP-AAV is an efficient vector for generating iN cells from astrocytes in vivo.

Key words: astrocyte-to-neuron conversion in vivo; cell fate determination; induced neuronal (iN) cells; proneural gene Ascl1; transdifferentiation

\section{Introduction}

Many transcription factors and chromatin-modifying processes play important roles in controlling the stability of the differentiated cellular identity (Holmberg and Perlmann, 2012). However, recent studies of induced pluripotent stem cells (Gurdon, 2006; Takahashi and Yamanaka, 2006) demonstrated that differentiated cells are not irreversibly locked in their mature identity and can be dedifferentiated by overexpression of selective transcription factors.

More recent findings that defined transcription factors can directly convert fibroblasts to functional neurons further demon-

Received Sept. 25, 2014; revised May 11, 2015; accepted May 11, 2015.

Author contributions: Y.L., Q.M., X.Z., and L.C. designed research; Y.L., Q.M., J.Y., S.H., P.Z., S.L., Z.R., W.Z., Q.Y., and J.G. performed research; Y.L., Q.M., X.Z., and L.C. analyzed data; Y.L., Q.M., X.Z., and L.C. wrote the paper.

This work was supported by the 973 Program from The Ministry of Science and Technology of China Grants 2015 CB964500 (L.C.) and 2011CBA00403 (X.Z.), National Natural Science Foundation of China Grants 31321091 and 31371096 (L.C.), and "Strategic Priority Research Program" of the Chinese Academy of Sciences Grant XDA01020306 (L.C.). We are grateful to Dr. M.-m. Poo for critical reading of and comments on this manuscript, Dr. Y. Yanagawa (Gunma University, Gunma, Japan) for providing Gad67-GFP knock-in mice, Dr. A. Eisch (University of Texas Southwestern, Dallas, TX) for providing Nestin-CreERT2 mice, and Chenyan Ma for technical assistance and reagents.

The authors declare no competing financial interests.

*Y.L. and Q.M. contributed equally to this work.

${ }^{\dagger}$ X.Z. and L.C. contributed equally to this work as joint senior authors.

Correspondence should be addressed to either of the following: Leping Cheng, Institute of Neuroscience and State Key Laboratory of Neuroscience, Shanghai Institutes for Biological Sciences, Chinese Academy of Sciences, 320 Yue Yang Road, Shanghai 200031, China, E-mail: Ipcheng@ion.ac.cn; or Xiaohui Zhang, State Key Laboratory of Cognitive Neuroscience and Learning, and IDG/McGovern Institute for Brain Research, Beijing Normal University, Beijing 100875, China, E-mail: xhzhang@bnu.edu.cn.

DOI:10.1523/JNEUROSCI.3975-14.2015

Copyright $\odot 2015$ the authors $\quad 0270-6474 / 15 / 359336-20 \$ 15.00 / 0$ strate the feasibility of transdifferentiation of non-neuronal cells directly into neurons (Yang et al., 2011). For examples, postnatal astrocytes of the mouse cerebral cortex can be converted into glutamatergic and GABAergic neurons after overexpression of the transcription factors Neurog2 and Dlx2, respectively (Berninger et al., 2007b; Heinrich et al., 2010). Several studies further showed that non-neuronal cells could be reprogrammed into neurons or neuroblasts in vivo (Buffo et al., 2005; Ohori et al., 2006; Grande et al., 2013; Niu et al., 2013; Torper et al., 2013; Guo et al., 2014; Su et al., 2014). However, it remains poorly understood how astrocyte-to-neuron conversion occurs in vivo and whether these induced neuronal (iN) cells could be incorporated into the preexisting neural circuits (Arlotta and Berninger, 2014).

Proneural proteins, including achaete-scute complex homologlike 1 (Ascl1; also known as Mash1), Neurog1-3, and Math1, control the commitment of multipotent progenitors to a neuronal fate (Bertrand et al., 2002). The expression of Ascl1 or Neurog2 in forebrain progenitor cells promotes the generation of GABAergic and glutamatergic neurons, respectively (Parras et al., 2002; Berninger et al., 2007a). Furthermore, Neurog2 and Ascl1 are capable of reprogramming astrocytes from the early postnatal cerebral cortex (Berninger et al., 2007b). Nevertheless, the efficiency of cortical astrocyte-to-neuron conversion induced by Ascl1 was only half of that by Neurog2 (Heinrich et al., 2010). In addition, overexpression of Neurog2 alone in postnatal cortical astrocytes gave rise to synapse-forming glutamatergic neurons, whereas it is unknown whether Ascll alone could direct postnatal 
cortical astrocytes toward synapse-forming GABAergic neurons (Heinrich et al., 2010).

Increasing evidence supports the notion that the astrocyte lineage is remarkably heterogeneous (Hewett, 2009; Zhang and Barres, 2010). It is conceivable that the origin of astrocytes may contribute to the outcome of the astrocyte-to-neuron conversion. In this study, we found that a single transcription factor, Ascll, can efficiently convert postnatal astrocytes from mouse dorsal midbrain into functional, synapse-forming neurons in vitro. Moreover, we designed an astrocyte-targeting gene delivery system in vivo and found that a single transcription factor Ascl1 alone can induce astrocyte-to-neuron conversion in vivo.

\section{Materials and Methods}

Mouse strains. The generation of glutamic acid decarboxylase 67 (Gad67)-GFP knock-in mice was described previously (Kaneko et al., 2008). The glial fibrillary acidic protein (GFAP)-GFP mice were kindly donated by Dr. Albee Messing (University of Wisconsin-Madison, Madison, WI) and obtained from The Jackson Laboratory (Zhuo et al., 1997). The mouse strains Aldh1l1-EGFP and Aldh1l1-Cre were obtained from the Mutant Mouse Regional Resource Center and were donated by the National Institute of Neurological Disorders and Stroke-funded GENSAT (Gene Expression Nervous System Atlas) BAC transgenic project (Gong et al., 2003, 2007). Gad67-GFP, GFAP-GFP, and Aldh1l1-GFP mice were identified with the primers $5^{\prime}$-GCACGACTTCTTCAAGT CCGCCATGCC-3' and 5'-GCGGATCTTGAAGTTCACCTTGATG CC-3', which were used for detecting the GFP expression. The hGFAPCreERT2 mice were kindly donated by Dr. Flora Vaccarino (Yale University, New Haven, CT) and obtained from The Jackson Laboratory (Ganat et al., 2006). The Rosa26-CAG-tdTomato (Ai9) mice were kindly donated by Dr. Hongkui Zeng (Allen Institute for Brain Science, Seattle, WA) and obtained from The Jackson Laboratory (Madisen et al., 2010). For induction in $h G F A P-C r e E R ; A i 9$ transgenic mice, an intraperitoneal injection of 4-hydroxytamoxifen (4-OHT; H6278; Sigma), dissolved at a concentration of $1 \mathrm{mg} / \mathrm{ml}$ in a 1:19 mixture of ethanol and sunflower oil at $33 \mathrm{mg} / \mathrm{kg}$ body weight, was administered once a day at postnatal day 12 (P12) to P14 or P12-P16. Aldh1l1-Cre and hGFAP-CreERT2 mice were identified with the primers $5^{\prime}$-GCCTGCATTACCGGTCGATGC- 3 ' and 5'-CAGGGTGTTATAAGCAATCCCC-3', which were used for detecting the Cre expression (Huang et al., 2010). Genotyping primers for identifying Ai9 mice were provided by The Jackson Laboratory. NestinCreERT2 mice (Lagace et al., 2007; kind gift from Dr. Amelia Eisch, University of Texas Southwestern, Dallas, TX) were crossed with $R 26 R-$ Stop-yellow fluorescent protein (YFP) mice (The Jackson Laboratory) to generate Nestin-CreER;Rosa26-YFP mice. For induction in adult Nestin-CreER;Rosa26-YFP mice, an intraperitoneal injection of tamoxifen (T5648; Sigma), dissolved at a concentration of $20 \mathrm{mg} / \mathrm{ml}$ in a 1:19 mixture of ethanol and sunflower oil at $100 \mathrm{mg} / \mathrm{kg}$ body weight, was administered once a day for $7 \mathrm{~d}$. For BrdU labeling, an intraperitoneal injection of BrdU (Sigma) at $100 \mathrm{mg} / \mathrm{kg}$ body weight was administered twice a day. Mice of both sexes were used in this study. All animal procedures are contained in protocols reviewed and approved by the Animal Care Committee at the Institute of Neuroscience, Shanghai Institutes for Biological Sciences, Chinese Academy of Sciences (Reference NA-100426) and at the State Key Laboratory of Cognitive Neuroscience and Learning at Beijing Normal University (Reference NKLCNL-2013-10).

Astrocyte culture. Primary cultures of astrocytes were prepared as described previously (McCarthy and de Vellis, 1980) with modifications. Briefly, the dorsal midbrain from P5-P7 mice were isolated and dissociated with $0.25 \%$ trypsin for $15 \mathrm{~min}$. The tissue was triturated for dissociation and plated with $10 \%$ serum in DMEM/F-12 (Invitrogen) medium. After 7-9 d, the oligodendrocytes were shaken off to obtain the astrocyte culture and replated in a medium consisting of DMEM/F-12, $10 \%$ fetal bovine serum (Invitrogen), penicillin/streptomycin (Invitrogen), and supplemented with B27 (Invitrogen), $10 \mathrm{ng} / \mathrm{ml}$ epidermal growth factor (EGF), and $10 \mathrm{ng} / \mathrm{ml}$ fibroblast growth factor 2 (FGF2). The vast majority of the cells (>90\%) in these cultures were positive for GFAP.
Plasmid construction and lentiviral transduction. Mouse Ascl1 full-length cDNA was cloned into the lentiviral expression vector FUGW-IRES-EGFP (Naldini et al., 1996) to generate FUGW-Ascl1. FUW-Ascl1-tdTomato was made by replacing GFP with tdTomato in the plasmid FUGW-Ascll. The empty lentiviral expression vector FUGW or FUW-tdTomato was used as a negative control. Lentiviral packaging and transfection were performed as described previously (Tiscornia et al., 2006). Lentiviral transduction of astrocytes cultured was performed $24 \mathrm{~h}$ after replating. Twenty-four hours after transduction, the medium was replaced completely by a medium consisting of DMEM/ F-12, B27 supplement, GlutaMAX, and penicillin/streptomycin. From 6 to $7 \mathrm{~d}$ post-injection (DPI) onward, brain-derived neurotrophic factor $(20 \mathrm{ng} / \mathrm{ml}$; PeproTech) were added to the medium every $3 \mathrm{~d}$ by changing $50 \%$ of the medium.

To generate GFAP-adeno-associated virus (AAV) vectors, the CMV promoter of AAV vector AAV-FLEX-Arch-GFP vector (Addgene) was replaced with the $h G F A P$ promoter $(2.2 \mathrm{~kb})$. mCherry then was inserted into the AAV vector to generate AAV-mCherry, and Ascll was cloned into the AAV-mCherry to generate AAV-Ascl1/mCherry. Ascl1 was cloned into the vector AAV-FLEX-Arch-GFP vector to generate AAVFLEX-Ascl1/GFP. The viral vectors AAV-mCherry and AAV-FLEXNLSGFP were used as negative controls [amino acid sequence of the nuclear localization signal (NLS) is VPKKKRKVEA (Kalderon et al., 1984)]. Recombinant AAV stocks, serotype 8, were produced by SBO Medical Biotechnology. The purification method used $\mathrm{CsCl}$ density gradients and desalting and concentrating on Amicon Ultra-15 centrifugal filter units (Grieger et al., 2006). Purified AAV viruses were titered using a quantitative PCR-based method.

Immunostaining. Immunostaining on cultured cells was performed essentially a described previously except the primary antibodies were incubated for overnight (Vierbuchen et al., 2010). Immunostaining on cryostat sections were performed as described previously (Huang et al., 2010). Double staining that combined in situ hybridization with immunostaining on cryostat sections was performed as described previously (Guo et al., 2012). In situ hybridization was performed first with a lower proteinase $\mathrm{K}$ concentration ( $1-2 \mu \mathrm{g} / \mathrm{ml}$ ) and shorter digesting time (3-7 min). After color development with nitroblue tetrazolium/5-bromo-4chloro-3-indolyl-phosphate as substrates, immunostaining procedures to detect mCherry proteins were performed. To generate the confocal images, the bright-field images of in situ hybridization signals were converted into pseudo-green fluorescent color and then merged with the fluorescent red mCherry images in Adobe Photoshop (Adobe Systems).

Primary antibodies were as follows: mouse anti-GFAP (1:1000; MAB360; Millipore), rabbit GFAP (1:1000; Z0334; DAKO), mouse antiTuj1 (1:500; MMS-435P; Covance), mouse anti-Map2 (1:500; M4403; Sigma), rabbit anti-GFP (1:1000; A6455; Invitrogen), chicken anti-GFP (A10262; 1:1000; Invitrogen), mouse anti-NeuN (1:100; MAB377; Millipore), rabbit anti-synapsin I (AB1543; 1:1000; Millipore), rabbit antiGABA (A2052; 1:3000; Sigma), mouse anti-GAD67 (MAB5406; 1:200; Millipore), guinea pig anti-vesicular GABA transporter (VGAT; 1:200; 131004; Synaptic Systems), rabbit anti-Discosoma red (DsRed; 1:500; 632496; Clontech), mouse anti-DsRed (1:100; sc-81595; Santa Cruz Biotechnology), guinea pig anti-VGLUT2 (1:400; VGluT2-GP-Af810; Frontier Institute), rabbit anti-acyl-CoA synthetase bubblegum family member 1 (Acsbg1; 1:100; ab65154; Abcam), rabbit anti-Sox2 (1:500; AB5603; Millipore), mouse anti-S100 $\beta$ (1:1000; S2532; Sigma), rabbit anti-excitatory amino acid transporter 1 (1:500; ab416; Abcam), mouse anti-glutamine synthetase (GS; 1:200; 610518; BD Biosciences), rabbit anti-NG2 (1:200; AB5320; Millipore), rabbit anti-ionized calciumbinding adapter molecule 1 (IBAI; 1:500; 019-19741; Wako), mouse antiCNPase (1:500; ab6319; Abcam), mouse anti-O4 (1:500; MAB345; Millipore), rabbit anti-Olig2 (1:500; AB9610; Millipore), rabbit antidoublecortin (DCX; 1:500; ab77450; Abcam), mouse anti-Ascl1 (1:200; 556604; BD Biosciences), rabbit anti-Ki67 (1:200; RM-9106; Thermo Fisher Scientific), mouse anti-BrdU (1:200; B2531; Sigma), and mouse anti-GST- $\pi$ (1:50; 610718; BD Biosciences). FITC-, Cy3-, and Cy5conjugated secondary antibodies were obtained from Jackson ImmunoResearch. AlexaFluor-350-, Alexa Fluor-488-, and Alexa Fluor546-conjugated secondary antibodies were obtained from Invitrogen. 
Stereotactic injection of $A A V$ virus. Mice were anesthetized with ketamine (100 mg/kg, i.p.)/xylazine (10 mg/kg, i.p.). An injecting pipette, with a tip opening size of $18-20 \mu \mathrm{m}$ (in diameter), was pulled from a glass tube. Viruses were injected into the dorsal midbrain, striatum, and cortex according to the mouse brain atlas (Paxinos and Franklin, 2001) at the following coordinates: (1) for the midbrain, anteroposterior (AP), -3.3 and $-4.1 \mathrm{~mm}$; mediolateral (ML), $0.5 \mathrm{~mm}$; dorsoventral (DV), $-1.0 \mathrm{~mm}$; (2) for the striatum, AP, $1.0 \mathrm{~mm}$; ML, $\pm 2.0 \mathrm{~mm}$; DV,-3.0 $\mathrm{mm}$; and (3) for the cortex, AP, $-1.25 \mathrm{~mm}$; ML, $1.4 \mathrm{~mm}$; DV, $-1.25 \mathrm{~mm}$, angled $90^{\circ}$ toward the midline in the coronal plane. After each injection, the pipette was left in the tissue for $10 \mathrm{~min}$ before slowly being withdrawn. For generating the stab injury model in the dorsal midbrain, viruses were injected by a $5 \mathrm{ml}$ syringe and a 31 gauge needle. The needle injection itself was used as a stab injury model. Virus stocks were diluted to $5 \times 10^{12}$ vector genomes $/ \mathrm{ml}$, and one microliter virus was injected into each site. After injection, the tissues were collected for immunostaining or slice recording.

Flow cytometry and quantitative RT-PCR. mCherry-expressing $\left(\mathrm{mCherry}^{+}\right.$) cells were sorted on a MoFlo XDP (Beckman Coulter). For qRT-PCR, total RNAs of mCherry ${ }^{+}$cells were extracted with TRIzol (Invitrogen), and the cDNA was synthesized using the Superscript III system (Invitrogen). Real-time qPCR was performed on a LightCycler 480 (Roche) using JumpStart ReadyMix (Sigma). The expression levels of genes of interest were normalized to the expression of Gapdh.

Neurosphere assay. The dorsal midbrain and the subventricular zone (SVZ) from mice at P12 were isolated and dissociated with papain (2 $\mathrm{mg} / \mathrm{ml}$ ) for $30 \mathrm{~min}$ at $37^{\circ} \mathrm{C}$. Cells were plated at a density of 1000 cells/ $\mathrm{cm}^{2}$ in ultra-low attachment six-well plates (Corning) in a medium (2 $\mathrm{ml}$ ) consisting of Neurobasal medium (Invitrogen), supplemented with B27 (Invitrogen), $2 \mu \mathrm{g} / \mathrm{ml}$ heparin, $10 \mathrm{ng} / \mathrm{ml} \mathrm{EGF}$, and $10 \mathrm{ng} / \mathrm{ml}$ FGF2. After $7 \mathrm{~d}$, the number of neurospheres was counted under a light microscope.

Slice preparation. Mice slices were prepared as described previously (Lu et al., 2007), with some modifications. Mice were anesthetized with sodium pentobarbital (50 mg/kg, i.p.; Nembutal; Abbott). After decapitation, the brain was dissected rapidly and placed in ice-cold oxygenated artificial CSF (aCSF) containing the following (in mM): $125 \mathrm{NaCl}, 3 \mathrm{KCl}$, $2 \mathrm{CaCl}_{2}, 2 \mathrm{MgSO}_{4}, 1.25 \mathrm{NaH}_{2} \mathrm{PO}_{4}, 1.3 \mathrm{Na}^{+}$-ascorbate, $0.6 \mathrm{Na}^{+}$pyruvate, $26 \mathrm{NaHCO}_{3}$, and 11 glucose, at $\mathrm{pH}$ 7.4. A coronal section was made with a vibratome (VT-1200S; Leica), and slices (300 $\mu \mathrm{m}$ thick) were maintained in an incubation chamber with oxygenated $(95 \%$ $\mathrm{O}_{2} / 5 \% \mathrm{CO}_{2}$ ) aCSF at $34^{\circ} \mathrm{C}$ for $30 \mathrm{~min}$ and then transferred to room temperature $\left(20-25^{\circ} \mathrm{C}\right)$ for $>30 \mathrm{~min}$ before being transferred to the recording chamber.

Electrophysiological recording. Whole-cell voltage- or current-clamp recording was performed as described previously (Lu et al., 2007; Zhang et al., 2009), with some modifications. Whole-cell recordings were made from $\mathrm{GFP}^{+}$or mCherry ${ }^{+}$cells with borosilicate glass micropipettes filled with an internal solution containing the following (in $\mathrm{mM}$ ): 130 K-gluconate, $20 \mathrm{KCl}, 10 \mathrm{HEPES}, 0.2 \mathrm{EGTA}, 4 \mathrm{Mg}_{2} \mathrm{ATP}, 0.3 \mathrm{Na}_{2} \mathrm{GTP}$, and $10 \mathrm{Na}_{2}$-phosphocreatine, at pH 7.3 (290-310 mOsm). Biocytin (0.2\%) was included in the internal solution for post-recording reconstruction of cell morphology. The pipette resistance was in the range of 2.0-4.0 $\mathrm{M} \Omega$. To evoke currents, step voltages $(500 \mathrm{~ms}, 10 \mathrm{mV}$ step) from -110 to $60 \mathrm{mV}$ were applied in the voltage-clamp mode. To evoke membrane potential deflections, step currents ( $500 \mathrm{~ms}$ duration) were injected in the current-clamp mode. In experiments recording the autaptic synaptic response, cells were voltage clamped at $-70 \mathrm{mV}$, and $1 \mathrm{~ms}$ voltage steps $(50-80 \mathrm{mV})$ were applied. A high $\mathrm{Cl}^{-}$internal solution was used to record GABAergic synaptic activities, and the solution was composed of the following (in mM): $94 \mathrm{~K}$-gluconate, $60 \mathrm{KCl}, 10 \mathrm{HEPES}, 0.2 \mathrm{EGTA}, 4$ Mg-ATP, $0.3 \mathrm{Na} 2 \mathrm{GTP}$, and 10 phosphocreatine. For separating spontaneous EPSCs (sEPSCs) and sIPSCs, cells were voltage clamped to -66 and $0 \mathrm{mV}$, respectively, using the Cs-based internal solution that contained the following (in mM): 125 Cs-gluconate, 5 tetraethylammoniumCl, $2 \mathrm{CsCl}$, 1 EGTA, 10 HEPES, 4 Mg-ATP, 0.3 GTP, 10 phosphocreatine, and $3 \mathrm{QX}-314, \mathrm{pH}$ 7.2. The combination of CNQX $(10 \mu \mathrm{M})$ and APV (50 $\mu \mathrm{M})$ or bicuculline $(20 \mu \mathrm{M})$ was used to block sEPSCs or sIPSCs. Electrical signals were amplified and filtered at $2-10 \mathrm{kHz}$ (low pass) with Axon
MultiClamp 700B (Molecular Devices), digitized at 20-100 kHz (Digidata 1322A; Molecular Devices), and acquired by a computer with the pClamp 9.2 (Molecular Devices). The data analysis was done with the Clampfit and a custom program in MATLAB (MathWorks). All chemicals were from Sigma or Tocris Bioscience.

Reconstruction of cell morphology. Reconstruction of cell morphology was performed as described previously (Lu et al., 2007), with some modifications. Slices containing recorded cells that were filled with biocytin $(0.2 \%)$ through the recording pipette were incubated at $4^{\circ} \mathrm{C}$ with $4 \%$ paraformaldehyde in $0.1 \mathrm{M} \mathrm{PBS}, \mathrm{pH}$ 7.4. After the fixation, slices were rinsed in PBS ( 5 min for three times), then blocked in $5 \%$ bovine serum albumin (BSA) and $0.5 \%$ Triton X-100 in PBS for $1 \mathrm{~h}$, and finally incubated in the PBS solution containing Alexa Fluor 488-conjugated strepavidin, $0.3 \%$ Triton $\mathrm{X}-100$, and $3 \% \mathrm{BSA}$ overnight at $4^{\circ} \mathrm{C}$. After three 5 min washings in PBS, the stained sections were mounted onto glass slides, air dried, and coverslipped with mounting medium. The fluorescence staining signals were acquired by a Nikon Al confocal microscope using a $20 \times$ objective.

Data analysis. Data were presented as mean \pm SEM. The statistical significance was tested with the unpaired Student's $t$ test. For electrophysiological recording data with non-normal distributions, statistical significance was tested with the nonparametric Kolmogorov-Smirnov test instead. Differences were considered significant at $p<0.05$.

\section{Results}

\section{Ascl1 converts dorsal midbrain astrocytes into neurons}

It was reported that Ascl1 was less efficient than Neurog2 in converting cortical astrocytes into neurons (Heinrich et al., 2010). During development, Ascl1 is required for the generation of GABAergic neurons in the domains $\mathrm{m} 1-\mathrm{m} 2$ of the dorsal midbrain (Peltopuro et al., 2010). To examine whether the origin of astrocytes plays a role in generating iN cells, we infected in vitro the astrocytes obtained from dorsal midbrain with the lentivirus FUGW-Ascl1, which expresses Ascl1 under the ubiquitin promoter. The starting astrocytes at $3 \mathrm{~d}$ after plating were characterized by the expression of distinct cell type markers (data not shown). At 10 DPI with the control lentivirus FUGW expressing only GFP, the astrocytes maintained the glial morphology and expressed the astrocyte marker GFAP but not the neuronal marker Tuj1 (Fig. 1 $A, B$ ). In contrast, most of the astrocytes that were infected with FUGW-Ascl1 adopted a neuronal fate and expressed Tuj1 $\left(76.8 \pm 6.4 \%, n=3,348-384 \mathrm{GFP}^{+}\right.$cells each) and exhibited characteristic neuronal morphology (Fig. 1C). Furthermore, astrocytes infected with FUGW-Ascll expressed the mature neuronal makers MAP2 and synapsin I at 21 DPI (Fig. $1 D, E)$.

To test whether the iN cells induced by Ascll are functional, we performed whole-cell recordings from these cells (Fig. $1 F$ ). We found that, at 30-40 DPI, all $\mathrm{GFP}^{+}$cells (63 of 63) were capable of generating action potentials (APs) in response to the injection of depolarizing step currents in current-clamp mode (Fig. 1G). Moreover, spontaneous postsynaptic currents were observed (in the voltage-clamp mode) in the majority of iN cells recorded ( $87.3 \%, 55$ of 63 cells) at 30-40 DPI (Fig. $1 G)$, suggesting that these neurons formed afferent synapses.

We also examined whether there were glutamatergic and GABAergic neurons in the iN cells by performing electrophysiological recording. We found that, at 30-40 DPI, electrical stimulation of $\mathrm{GFP}^{+}{ }^{+} \mathrm{iN}$ cells with depolarizing voltages often resulted in the activation of their autapse(s), as shown by the evoked postsynaptic currents recorded in the same iN cells immediately after the stimulation (Fig. $1 H$ ). These autaptic currents could be fully blocked by bath application of CNQX $(10 \mu \mathrm{M})$, a reversible antagonist of AMPA/kainate glutamate receptors (Fig. $1 H$ ), indicating their glutamatergic nature. Such autaptic responses were ob- 

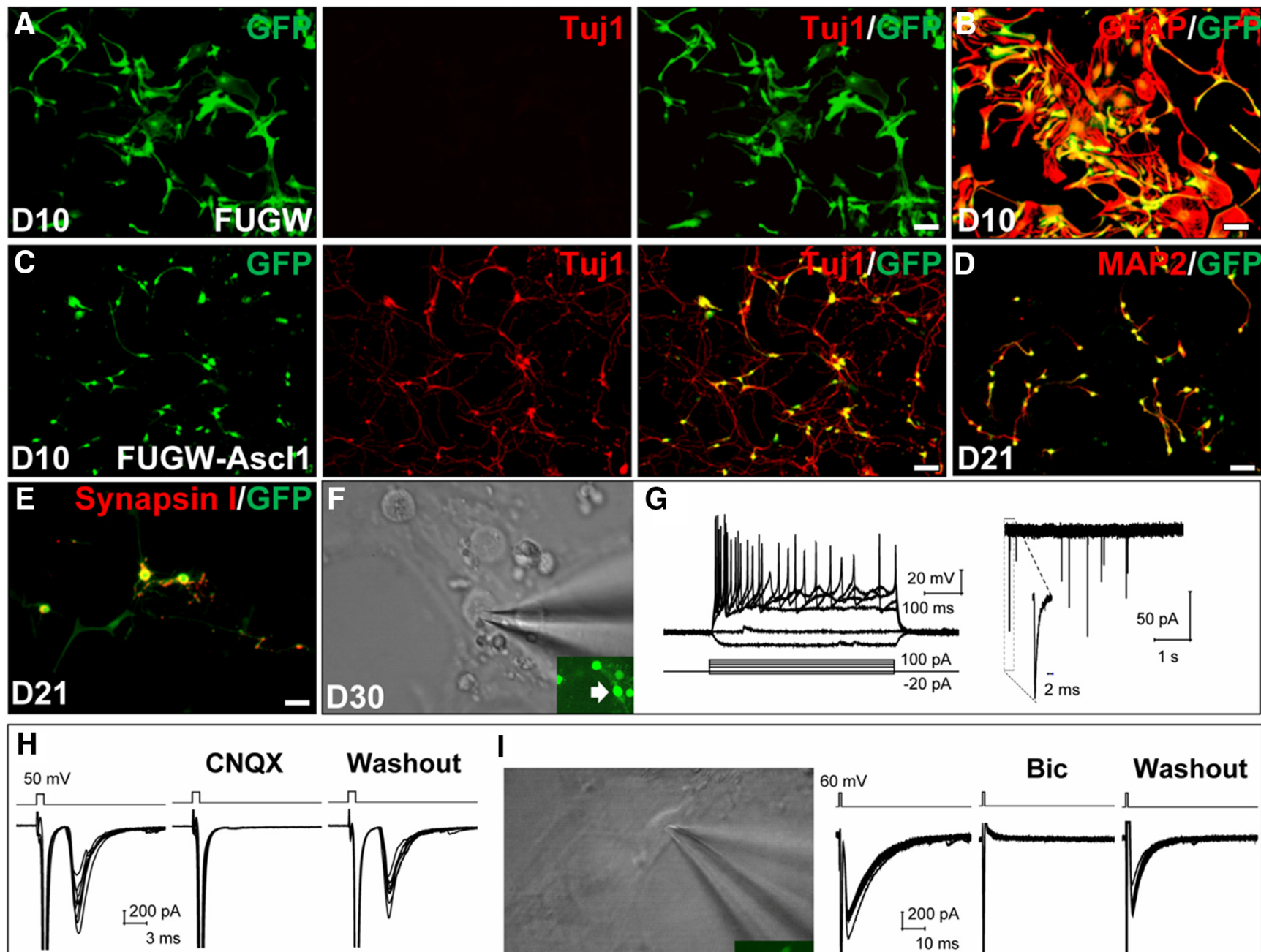

D30
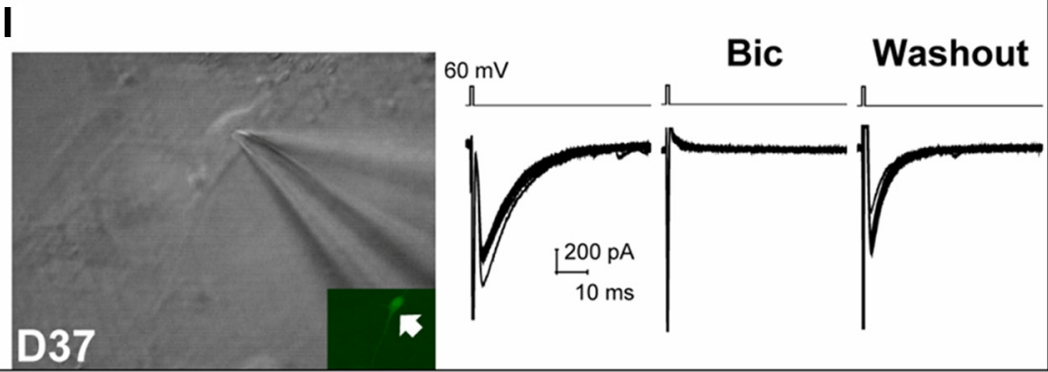

Figure 1. Ascl1 converts dorsal midbrain astrocytes into neurons in vitro. $\boldsymbol{A}, \boldsymbol{B}$, Cells infected with the control lentivirus FUGW expressing GFP (green) did not express Tuj1 (A) but expressed GFAP (red) and displayed astrocyte morphology (B) $10 \mathrm{~d}$ after infection. C, Cells infected with lentivirus FUGW-Ascl1 expressing Ascl1 and GFP expressed Tuj1 (red) and displayed characteristic neuronal morphology $10 \mathrm{~d}$ after infection. $\boldsymbol{D}, \boldsymbol{E}$, Cells infected with lentivirus FUGW-Ascl1 expressed the mature neuronal markers MAP2 $(\boldsymbol{D})$ and synapsin I $(\boldsymbol{E})$ at 21 DPI. $\boldsymbol{F}$, Differential interference contrast (DIC) image of whole-cell recording from an iN cell (green fluorescence, arrow) at $30 \mathrm{DPI}$. G, Traces of membrane potentials of the iN cell shown in $\boldsymbol{F}$ in response to the intracellular injection of step currents (ranging from - 20 to 100 pA; $500 \mathrm{~ms}$ ) under current-clamp mode (left) and of spontaneous postsynaptic currents (sPSCs) under voltage-clamp mode. Inset, An example of sPSCs showed at a higher time resolution. $\boldsymbol{H}$, An example of glutamatergic autaptic synaptic currents recorded from an iN cell at 30 DPI. The autaptic responses were evoked by a voltage step ( $50 \mathrm{mV}, 1 \mathrm{~ms})$ in the voltage-clamp mode. Application of CNQX (10 $\mu \mathrm{m}$ ) reversibly blocked the autaptic responses. I, DIC image of whole-cell recording from an induced GABAergic neuron (green fluorescence, arrow) at 37 DPI from the astrocyte of the Gad67-GFP mouse and GABAergic autaptic synaptic currents evoked by a voltage step ( $60 \mathrm{mV}, 1 \mathrm{~ms}$ ) in the voltage-clamp mode. Application of bicuculline (Bic; 20 $\mu \mathrm{m})$ reversibly blocked the autaptic responses. Scale bars: $\boldsymbol{A}-\boldsymbol{D}, 100 \mu \mathrm{m} ; \boldsymbol{E}, 50 \mu \mathrm{m}$.

served in 7 of 36 neurons examined (19.4\%), and the blocking effect of CNQX was observed consistently in all three neurons tested.

To determine whether there were presynaptically competent GABAergic neurons in the iN cells, we infected lentivirus FUWAscl1-tdTomato into the astrocytes that were isolated from the dorsal midbrain of Gad67-GFP knock-in mice (Kaneko et al., 2008). To facilitate synaptogenesis of the iN cells, astrocytes that had been infected by FUW-Ascl1-tdTomato for $10 \mathrm{~d}$ were cocultured with neurons isolated from the dorsal midbrain of P5-P7 wild-type (WT) mice. Among these induced GAD67 ${ }^{+}$neurons $\left(\right.$ tdTomato ${ }^{+} \mathrm{GFP}^{+}$cells), we recorded typical autaptic responses in 8 of 38 neurons, and application of the $\mathrm{GABA}_{\mathrm{A}}$ receptor antagonist bicuculline $(20 \mu \mathrm{M})$ abolished this autaptic transmission in all five cells tested (Fig. 1I). Thus, there were induced GABAergic neurons in the iN cells, and they were capable of forming synapses.

The presence of glutamatergic and GABAergic iN cells was corroborated by additional immunostaining of the glutamatergic marker VGLUT2 and the GABAergic markers GABA, GAD67 (encoded by the gene Gad1), and VGAT (data not shown). Together, the above studies showed that the transcription factor Ascl 1 could efficiently convert postnatal dorsal midbrain astrocytes in vitro into neurons that could be functionally glutamatergic or GABAergic.

GFAP-AAV vectors efficiently infect dorsal midbrain astrocytes in vivo

To explore the possibility of converting astrocytes into neurons in vivo, we chose the recombinant AAV vectors to deliver the genes into the mouse midbrain (superior colliculi and inferior colliculi in one hemisphere), using the GFAP promoter (Su et al., 2004). We constructed AAV vectors containing the $h$ GFAP promoter and sequence that code for mCherry alone or Ascll fused with mCherry and injected the vector into one side of the tectum of WT mice at P12-P15, when astrocytes are known to lose their 
neurosphere-generating potential (Laywell et al., 2000). We detected mCherry expression by immunostaining $3 \mathrm{~d}$ after AAV infection. Astrocytes are a heterogeneous mix of cells. By examining the morphology of AAV-mCherry-infected astrocytes, we found that most of the astrocytes looked like the "protoplasmic" type (data not shown). Ascl $1 / \mathrm{mCherry}$ is a fusion protein, and both Ascll and mCherry were expressed predominantly in the nuclei of cells that had been infected with AAV-Ascl1/mCherry virus. Double immunostaining of mCherry and the astrocyte marker Acsbg1 (Cahoy et al., 2008) showed that nearly all mCherry ${ }^{+}$ cells stained positively with Acsbgl at 3 DPI for both the control AAV-mCherry (96.1 $\pm 0.7 \%, n=3$ mice, $220-326$ cells per mice; Fig. 2A) and AAV-Ascl1/ mCherry (93.1 $\pm 2.7 \%, n=3$ mice, $130-$ 280 cells per mice; Fig. 2B), suggesting that the AAV vectors specifically targeted astrocytes. Furthermore, double immunostaining of mCherry and the neuronal marker NeuN showed that mCherry was barely expressed in neurons (Fig. $\left.3 A, A^{\prime}, D, D^{\prime}\right)$. In addition, mCherry was not coexpressed with NG2 (data not shown), a marker for NG2 cells, the ubiquitous oligodendrocyte precursors with restricted lineage potential in mammalian CNS (Kang et al., 2010).

To confirm the specific expression of GFAP-AAV vectors, we also used two astrocyte-specific reporter mouse lines, GFAP-GFP (Zhuo et al., 1997) and Aldh1l1-GFP (Cahoy et al., 2008), that express GFP specifically in astrocytes. Three days after infection with AAV-mCherry, we found that the vast majority of mCherry $^{+}$cells colocalized with $\mathrm{GFP}^{+}$ cells in both Aldh1l1-GFP mice (98.7 \pm $1.0 \%, n=3$ mice, $426-475$ cells per mice; Fig. 2C) and GFAP-GFP mice (93.5 \pm $1.4 \%, n=3$ mice, $123-186$ cells per mice; Fig. 2D). We also quantified the efficacy of viral infection to astrocytes by analyzing the percentage of mCherry ${ }^{+}$cells in Aldh1l1-GFP mice injected with AAV-Ascl1/mCherry at P12-P15. At 3 DPI, double immunostaining results showed that a small population of astrocytes (5.7 $\pm 3.2 \%, n=3$ mice, $124-156$ cells per mice) in the dorsal midbrain were infected. Last, to further confirm the identity of GFAPAAV-targeted cells at P12-P14, we analyzed intercrosses of GFAPCreERT2 (Ganat et al., 2006) with a conditional Rosa26-CAGtdTomato (Ai9) reporter line (Madisen et al., 2010) and induced GFAP-CreERT2;Rosa26-CAG-tdTomato mice with 4-OHT. The results showed that tdTomato was expressed in 4-OHT-treated mice, and double immunostaining of 4-OHT-treated mice showed that tdTomato colocalized extensively with Acsbg1 (93.8 \pm $1.6 \%, n=3$ mice, $169-177$ cells per mice; Fig. $2 E)$. Thus, AAV vectors driven by the GFAP promoter can specifically infect astrocytes at P12-P15 in vivo. (arrows). Scale bars, $20 \mu \mathrm{m}$.

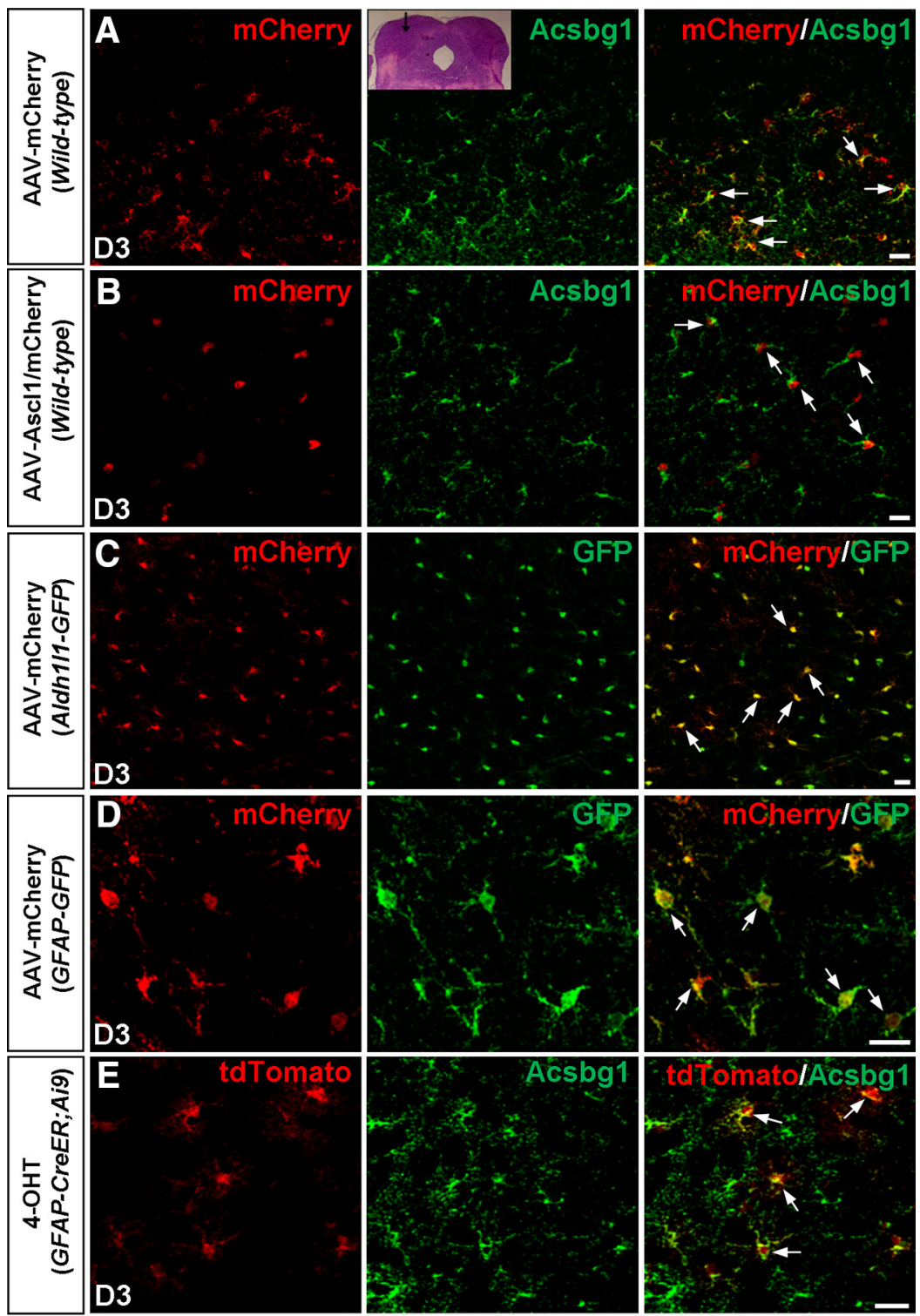

Figure 2. GFAP-AAV vectors target astrocytes of the dorsal midbrain in vivo. $A, B$, Double staining of $m$ Cherry and Acsbg1 on sections of the dorsal midbrain from WT mice infected with the control virus AAV-mCherry $(A)$ or virus AAV-Ascl1/mCherry $(B)$ at Derry was almost expressed exclusively in astrocytes. The inset shows the area where the $A A V$ viruses were injected. $C, D$, 政 Cherry at $3 \mathrm{DPI}$. mCherry extensively colabeled with GFP (arrows). E, Double staining of tdTomato and Acsbg1 on sections of the dorsal midbrain from GFAP-CreERT2;Ai9 mice that were injected with 4-OHT. tdTomato extensively colabeled with Acsbg1

In vivo conversion of dorsal midbrain astrocytes into neurons by Ascl1

After establishing the modified AAV vectors that were driven by the GFAP promoter to specifically deliver genes into astrocytes in the mouse midbrain, we further studied whether infected astrocytes are reprogrammed into neurons in vivo. We injected AAVmCherry or AAV-Ascl1/mCherry into the dorsal midbrain of WT mice at P12-P15 and collected the brain sections at several time points after AAV infection. Double immunostaining showed that mCherry barely colocalized with NeuN in midbrain tissue infected with control AAV-mCherry $(3.4 \pm 0.2 \%, n=3$ mice, 472-489 cells per mice; Fig. $\left.3 A, A^{\prime}\right)$ or AAV-Ascl1/ mCherry $(4.5 \pm 2.3 \%, n=3$ mice, $279-419$ cells per mice; Fig. $\left.3 D, D^{\prime}\right)$ at 3-5 DPI. At later time points, the vast majority of mCherry remained absent in $\mathrm{NeuN}^{+}$cells in control AAV- 

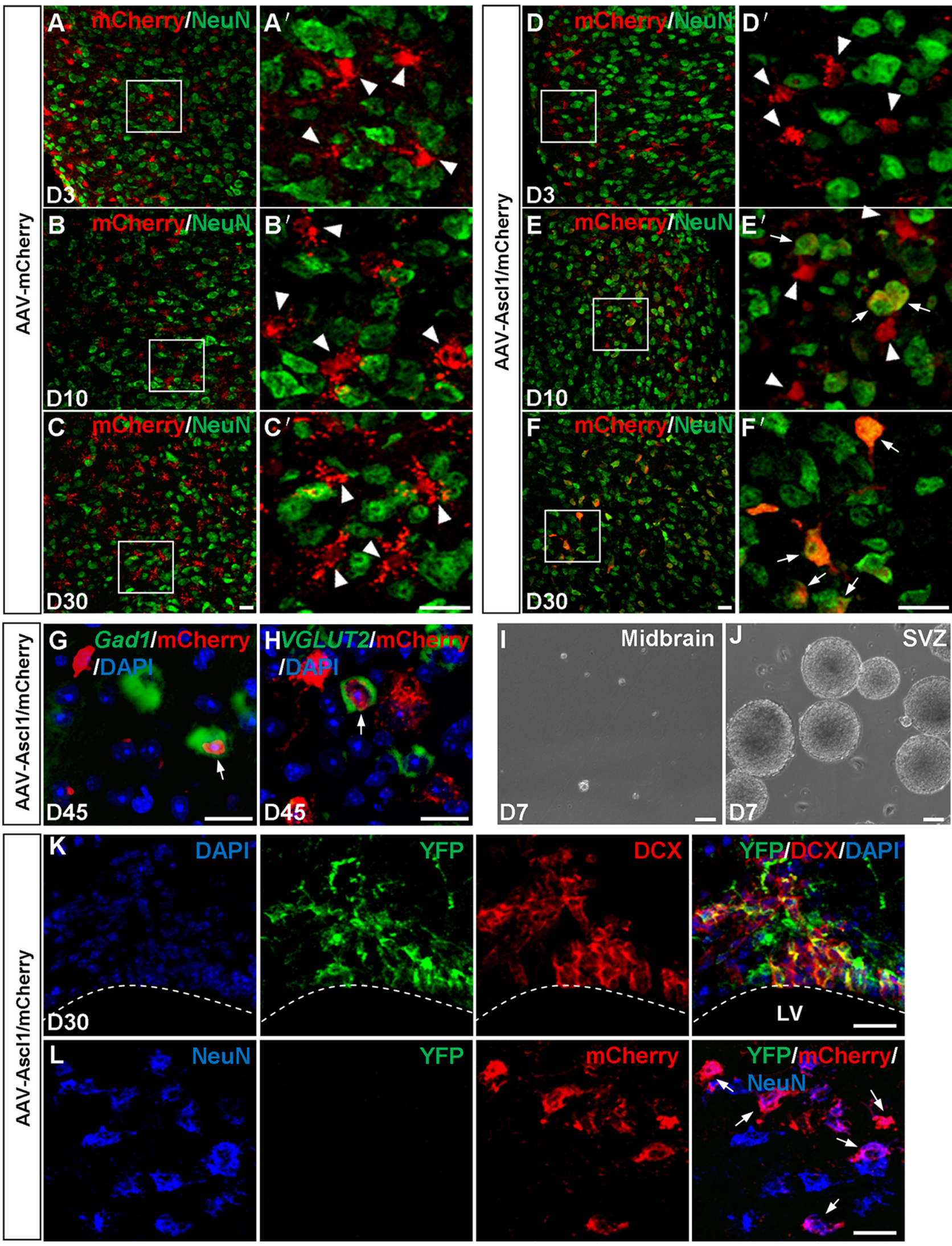

Figure 3. Conversion of dorsal midbrain astrocytes into neurons by $A s c 17$ in vivo. $A-C^{\prime}$, Double staining of $m$ Cherry and NeuN on sections of the dorsal midbrain from WT mice that were infected with the control virus AAV-mCherry on day $3\left(\boldsymbol{A}, \boldsymbol{A}^{\prime}\right)$, day $10\left(\boldsymbol{B}, \boldsymbol{B}^{\prime}\right)$, and day $30\left(\boldsymbol{C}, \boldsymbol{C}^{\prime}\right)$. mCherry was not colocalized with NeuN (arrowheads). $\boldsymbol{A}^{\prime}, \boldsymbol{B}^{\prime}$, and $\boldsymbol{C}^{\prime}$ are higher magnifications of the boxed areas in $\boldsymbol{A}, \boldsymbol{B}$, and $\boldsymbol{C}$, respectively. $\mathbf{D}-\boldsymbol{F}^{\prime}$, Double staining of mCherry and NeuN on sections of the dorsal midbrain from WT mice that were infected with virus $A A V-A s c l 1 / \mathrm{mCherry}$ on day $3\left(\boldsymbol{D}, \boldsymbol{D}^{\prime}\right)$, day $10\left(\boldsymbol{E}, \boldsymbol{E}^{\prime}\right)$, and day $30\left(\boldsymbol{F}, \boldsymbol{F}^{\prime}\right)$ after infection. mCherry was gradually colocalized with NeuN. $\boldsymbol{D}^{\prime}, \boldsymbol{E}^{\prime}$, and $\boldsymbol{F}^{\prime}$ are higher magnification of the boxed areas in $\boldsymbol{D}, \boldsymbol{E}$, and $\boldsymbol{F}$, respectively. $\boldsymbol{G}, \boldsymbol{H}$, Pseudo-color double staining of mCherry with Gad1 mRNA $(G$, red) or VGLUT2 $(\boldsymbol{H}$, red) on sections of the dorsal midbrain from WT mice that were infected with (Figure legend continues.) 
mCherry-infected tissues at 10-14 DPI (4.0 $\pm 0.5 \%, n=3$ mice, $325-487$ cells per mice; Fig. $\left.3 B, B^{\prime}\right)$ or at 28-32 DPI (3.9 $\pm 0.4 \%, n=3$ mice, $389-515$ cells per mice; Fig. $\left.3 C, C^{\prime}\right)$. In contrast, mCherry became progressively colocalized with NeuN in tissues infected by AAV-Ascl1/mCherry, with the percentage of cells showing that colocalization increased to $44.2 \pm 12.5 \%(n=3$ mice, $309-436$ cells per mice) at 10-14 DPI (Fig. $\left.3 E, E^{\prime}\right)$ and to $93.1 \pm 1.7 \%(n=3$ mice, $412-557$ cells per mice) at $28-32$ DPI (Fig. $3 F, F^{\prime}$ ).

We have also examined the transmitter phenotypes of the iN cells induced by Ascll and found that these cells expressed Gad1 (13.2 土 4.2\%, $n=3$ mice, 57-180 cells per mice; Fig. $3 G$ ) and VGLUT2 ( $6.5 \pm 2.2 \%, n=3$ mice, $48-118$ cells per mice; Fig. $3 \mathrm{H})$ at $45 \mathrm{DPI}$, indicating the presence of both glutamatergic and GABAergic neurons in these iN cells. In summary, Ascll could convert astrocytes of the dorsal midbrain into neurons efficiently in vivo.

To determine whether there are neural stem cells (NSCs) in the dorsal midbrain at P12, we performed the frequently adopted neurospheres assay (Pevny and Rao, 2003). The results showed that the dorsal midbrain was unable to generate neurospheres $(0.8 \pm 0.2$ neurospheres in each well of six wells, $n=3$ mice, $0-1$ neurospheres per mice; Fig. 3I), although cells from the SVZ of P12 mice could generate many neurospheres $(364.9 \pm 53.5$ neurospheres in each well of six wells, $n=$ 3 mice, 333-426 neurospheres per mice; Fig. $3 J)$. This is in line with the report that early postnatal astrocytes can give rise to neurospheres until P11 (Laywell et al., 2000). Meanwhile, to explore whether $\mathrm{GFAP}^{+}$cells are neural progenitors at

P12 that can give rise to neurons at later stages, we induced GFAP-CreERT2; Rosa26-CAG-tdTomato mice with five daily 4-OHT injections (at P12-P16) and examined the identity of tdTomato ${ }^{+}$cells $30 \mathrm{~d}$ later. Double immunostaining showed that tdTomato did not colocalize with NeuN (data not shown). To further confirm whether the iN cells were derived from NSCs, we use Nestin-CreER;Rosa26-YFP mice to label adult NSCs and their progeny in vivo. Ten days after induction of the expression of YFP, AAV-Ascl1/mCherry virus was injected into the dorsal

(Figure legend continued.) virus AAV-Ascl1/mCherry at $45 \mathrm{DPI} . I, J$, Neurosphere formation by cells derived from the dorsal midbrain (I) and the SVZ (J) of WT mice at P12. $K$, Immunostaining analysis showing $\mathrm{DCX}^{+}$cells within the lateral ventricle (LV) were derived from NSCs that were traced by YFP in Nestin-CreER;Rosa26-YFP mice. L, Triple staining of mCherry, NeuN, and YFP on sections of the adult dorsal midbrain from Nestin-CreER;Rosa26-YFP mice that had been treated with tamoxifen and injected with AAV-Ascl1/mCherry. Ascl1-induced NeuN ${ }^{+}$ cells (arrows) within the dorsal midbrain are YFP ${ }^{-}$, indicating that they are produced locally rather than derived from endogenous neurogenic niches. Scale bars: $A-H, K-L, 20 \mu \mathrm{m}, I, J, 50 \mu \mathrm{m}$. midbrain of these mice. Double immunostaining showed that immature neuronal marker DCX was colocalized with YFP in the lateral ventricle (Fig. $3 \mathrm{~K}$ ), indicating that $\mathrm{DCX}^{+}$cells were derived from NSCs. In contrast, no expression of YFP was detected in the dorsal midbrain in which iN cells were generated, suggesting that these cells were generated from local reprogramming instead of endogenous NSCs (Fig. $3 L$ ). These results indicate that iN cells derived from GFAP $^{+}$cells were converted from astrocytes instead of neural progenitors.

To further determine whether iN cells pass through a proliferative state in the reprogramming induced by Ascll, proliferating cells were continually labeled by intraperitoneal injection of BrdU at 3-7 and 3-30 DPI with the virus. At 7 DPI, doubleimmunostaining results showed that mCherry barely colocalized with BrdU in midbrain tissue infected with control AAVmCherry $(2.2 \pm 0.5 \%, n=3$ mice, $325-410$ cells per mice; Fig. $4 A)$ or AAV-Ascl1/mCherry $(1.6 \pm 0.3 \%, n=3$ mice, $213-307$ cells per mice; Fig. $4 B$ ). Then at $30 \mathrm{DPI}$, we found that mCherry still barely colocalized with BrdU in midbrain tissue infected with 


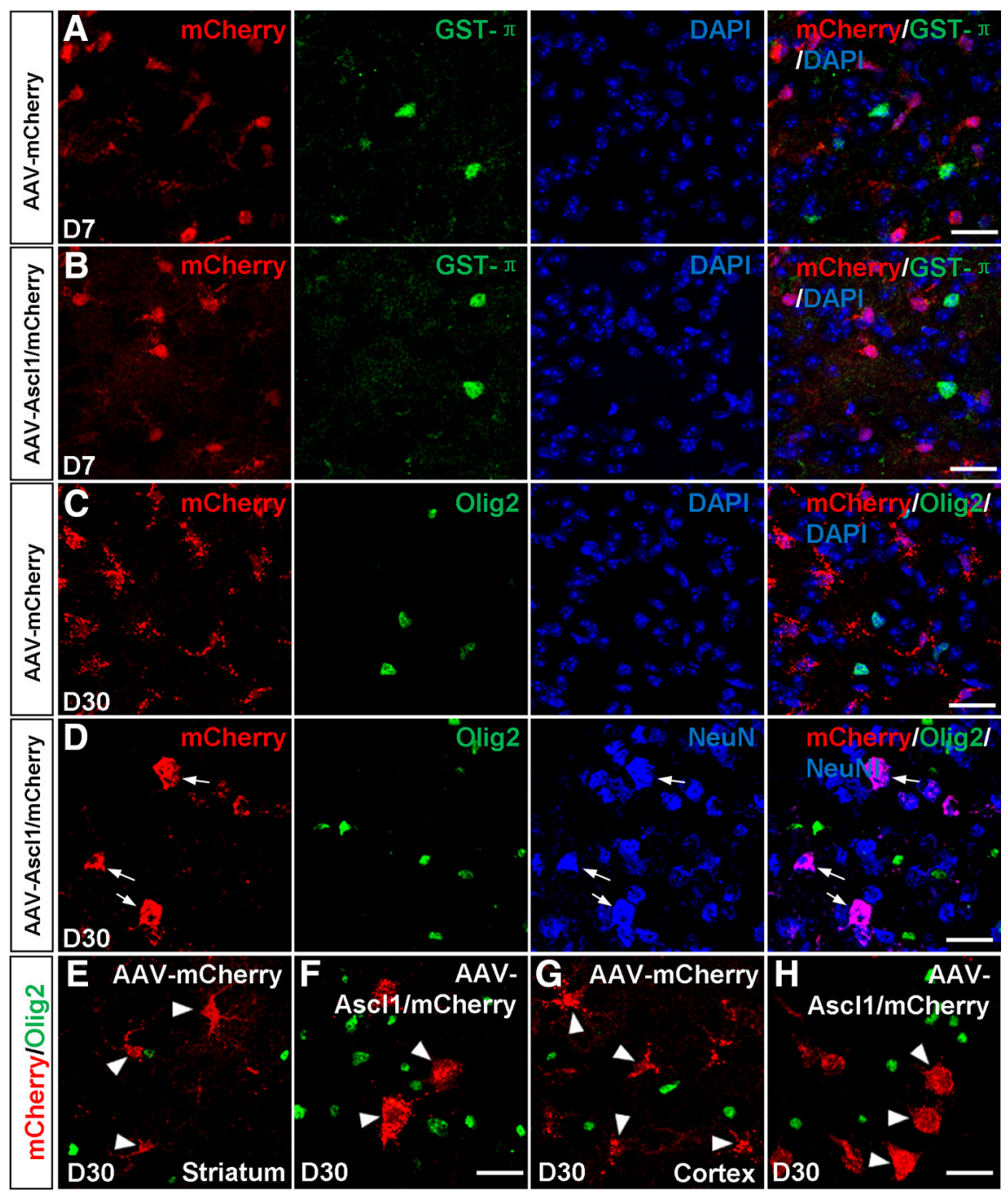

Figure 5. Ascl1 converts astrocytes to neurons but not oligodendrocytes. $\boldsymbol{A}, \boldsymbol{B}$, Double staining of mCherry and GST- $\pi$ on sections of the dorsal midbrain from WT mice infected with the control virus AAV-mCherry $(\boldsymbol{A})$ or virus AAV-Ascl1/mCherry $(\boldsymbol{B})$ at $7 \mathrm{DPI}$. mCherry was not colocalized with GST- $\pi$. C, Double staining of mCherry and 0 lig2 on sections of the dorsal midbrain from WT mice infected with the control virus AAV-mCherry $(\boldsymbol{C})$ at $30 \mathrm{DPI}$. mCherry was not colocalized with Olig2. D, Triple staining of mCherry, 0lig2, and NeuN on sections of the dorsal midbrain that were infected with AAV-Ascl1/mCherry at 30 DPI (D). mCherry was colocalized with NeuN but not with 0 lig2 (arrows). $\boldsymbol{E}, \boldsymbol{F}$, Double staining of $m$ Cherry and 0 lig2 on sections of the striatum from WT mice infected with the control virus AAV-mCherry $(\boldsymbol{E})$ or virus AAV-Ascl1/mCherry $(\boldsymbol{F})$ at $30 \mathrm{DPI}$. $\boldsymbol{G}, \boldsymbol{H}$, Double staining of $\mathrm{mCherry}$ and 0 lig2 on sections of the cortex from WT mice infected with the control virus AAV-mCherry (G) or virus AAV-Ascl1/ $\mathrm{mCherry}(\boldsymbol{H})$ at $30 \mathrm{DPI}$. Scale bars, $20 \mu \mathrm{m}$.

control AAV-mCherry ( $4.3 \pm 1.2 \%, n=3$ mice, $230-363$ cells per mice; Fig. $4 E)$ or AAV-Ascl1/mCherry $(1.6 \pm 1.0 \%, n=3$ mice, 204-290 cells per mice; Fig. $4 F$ ), whereas the vast majority of mCherry $^{+}$cells expressed $\mathrm{NeuN}$ in midbrain tissue infected with AAV-Ascl1/mCherry (Fig. $4 F$ ) but not in midbrain tissue infected with control AAV-mCherry (Fig. 4E). Furthermore, double-immunostaining results showed that mCherry barely colocalized with Ki67 in midbrain tissue infected with control AAV-mCherry $(1.0 \pm 0.6 \%, n=3$ mice, $192-246$ cells per mice; Fig. $4 C)$ or AAV-Ascl1/mCherry $(0.9 \pm 0.3 \%, n=3$ mice, $185-$ 276 cells per mice; Fig. $4 D$ ) at 15 DPI. At 30 DPI, mCherry still barely colocalized with Ki67 in midbrain tissue infected with control AAV-mCherry (data not shown) or AAV-Ascl1/mCherry $(0.5 \pm 0.1 \%, n=3$ mice, $171-248$ cells per mice; Fig. $4 G)$, whereas the vast majority of mCherry ${ }^{+}$cells expressed $\mathrm{NeuN}$ in midbrain tissue infected with AAV-Ascl1/mCherry (Fig. 4G) but not in midbrain tissue infected with control AAV-mCherry (data not shown). These results indicate that iN cells did not pass through a proliferative stage.

Two previous studies reported that Ascll overexpression induces oligodendrocytes in the adult spinal cord and dentate gyrus (Ohori et al., 2006; Jessberger et al., 2008). Then we examined whether astrocytes could be converted into oligodendrocytes by Ascl1. Doubleimmunostaining results showed that mCherry was barely colabeled with the oligodendrocytes marker GST- $\pi$ in the midbrain $7 \mathrm{~d}$ after infection of the control virus AAV-mCherry $(0.4 \pm 0.1 \%, n=3$ mice, $237-303$ cells per mice; Fig. $5 A$ ) or AAV-Ascl $1 /$ mCherry $(0.4 \pm 0.3 \%, n=3$ mice, $219-338$ cells per mice; Fig. $5 B$ ). At later time points, mCherry was barely colabeled with another oligodendrocytes marker, Olig2, in the midbrain infected with the control virus AAV-mCherry $(2.8 \pm 2.2 \%, n=3$ mice, $308-393$ cells per mice; Fig. $5 C$ ) or AAV-Ascl1/ mCherry $(3.3 \pm 0.4 \%, n=3$ mice, $278-$ 327 cells per mice; Fig. $5 D$ ) at $30 \mathrm{DPI}$, whereas the vast majority of mCherry cells expressed NeuN in the midbrain infected with AAV-Ascl1/mCherry (Fig. $5 D)$. These results indicate that astrocytes in the midbrain were converted into neurons but not oligodendrocytes by Ascll overexpression. In the meantime, we found that mCherry was barely colabeled with Olig2 in the striatum infected with the control virus AAV-mCherry (3.2 \pm $1.2 \%, n=3$ mice, $156-181$ cells per mice; Fig. $5 E$ ) or AAV-Ascl1/mCherry (4.4 \pm $1.7 \%, n=3$ mice, $137-199$ cells per mice; Fig. $5 F$ ) at 30 DPI. In the cortex, mCherry was also barely colabeled with Olig2 in tissue infected with the control virus AAVmCherry $(3.1 \pm 1.4 \%, n=3$ mice, $124-$ 197 cells per mice; Fig. $5 G$ ) or AAV-Ascl1/ mCherry $(3.2 \pm 1.4 \%, n=3$ mice, $119-$ 145 cells per mice; Fig. $5 H$ ) at 30 DPI. These results indicate that astrocytes in the striatum and cortex were not converted to oligodendrocytes by Ascll overexpression as well.

\section{Expression analysis of molecular markers of iN cells generated in vivo}

To determine the expression of molecular markers in iN cells, we isolated the mCherry ${ }^{+}$cells in the dorsal midbrain from WT mice that were infected with AAV-Ascl1/mCherry by fluorescence-activated cell sorting (FACS) on day 4, day 10, and day 30 after infection. Quantitative RT-PCR results showed that the expression of the astrocyte markers Gfap, S100 $\beta$, and Acsbg1 decreased (Fig. $6 A-C$ ) whereas the expression of the neuronal markers Tuj1, Map2, and NeuN increased in iN cells over time (Fig. $6 D-F$ ). The expression of the neuronal progenitor markers Sox 2 and Pax6 and the midbrain neural progenitor markers En1, En2, Pax3, and Pax7 could not be detected during the period 
examined (Fig. $6 G-I$ ). These results suggest that iN cells induced by Ascll in vivo gradually lost their astrocyte properties and became mature neurons.

\section{Functional characterization of iN cells generated in vivo}

We further examined the functional properties and the maturation of iN cells generated in vivo by performing wholecell recordings in acute brain slices obtained from infected mice at different time points after viral injection. The infected cells were identified by the expression of mCherry. In slices from mice infected with the control virus AAV-mCherry, we found that infected cells exhibited a relatively low membrane resistance (1.97 $\pm 0.88 \mathrm{M} \Omega, n=7)$, a more hyperpolarized membrane potential $(-79.2 \pm$ $0.4 \mathrm{mV}, n=14$ ), and no AP in response to intracellular injection of step currents (Fig. 7A). These properties were quantitatively comparable with those of astrocytes (Volterra and Meldolesi, 2005). The morphology of recorded cells as revealed by post-recording staining with biocytin also showed that they had typical astrocyte morphology and were coupled via gap junctions to neighboring astrocytes (Fig. $7 A$, fluorescence images). These results suggest that the control virus AAVmCherry specifically targeted astrocytes in vivo and did not change their physiological properties. In contrast, in brain slices from mice 7-30 d after infection of AAV-Ascl1/mCherry, we found that many infected cells displayed inward (putative $\mathrm{Na}^{+}$) and outward (putative $\mathrm{K}^{+}$) currents in the voltage-clamp mode, with the amplitude increased within days after infection (Fig. $7 B-E$ ). Consistently, in the current-clamp recordings, these cells showed an increased ability in generating APs within days after infection (Fig. $7 B-E$, traces). Furthermore, the morphology of recorded iN cells became more complex and less electrically coupled with neighboring cells over time, as shown by the post-recording biocytin staining (Fig. $7 B-E$, images). Last, there was also an increase in membrane resistance and a decrease of resting membrane potential (RMP) over time (Fig. $7 F, G$ ). All these properties indicated a progressive functional maturation of iN cells after the expression of the single transcription factor Ascl1 in vivo.

We further categorized the iN cells into four groups based on their current and voltage (spiking) response patterns: (1) nonactive cells ("non-active"); (2) cells exhibiting inward current without an AP ("inward"); (3) single AP ("sAP"); and (4) multiple APs ("mAP"). The results shown in Figure $7 \mathrm{H}$ indicated that these iN cells induced by Ascll in vivo became excitable gradually over time, and, by $30 \mathrm{DPI}$, all recorded iN cells were capable of spiking at high frequencies $(50-220 \mathrm{~Hz}$; Fig. $7 \mathrm{H})$. In contrast,
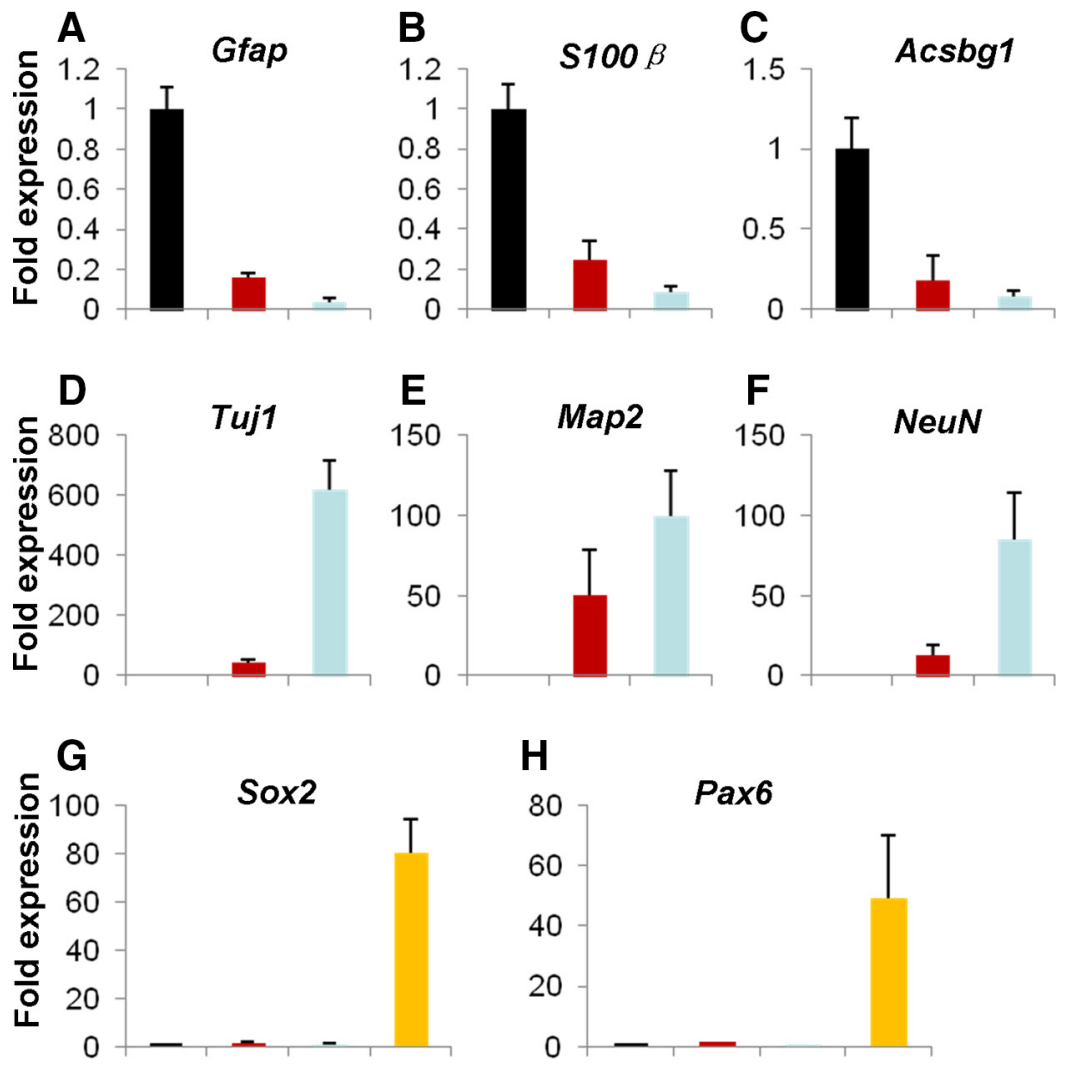

H
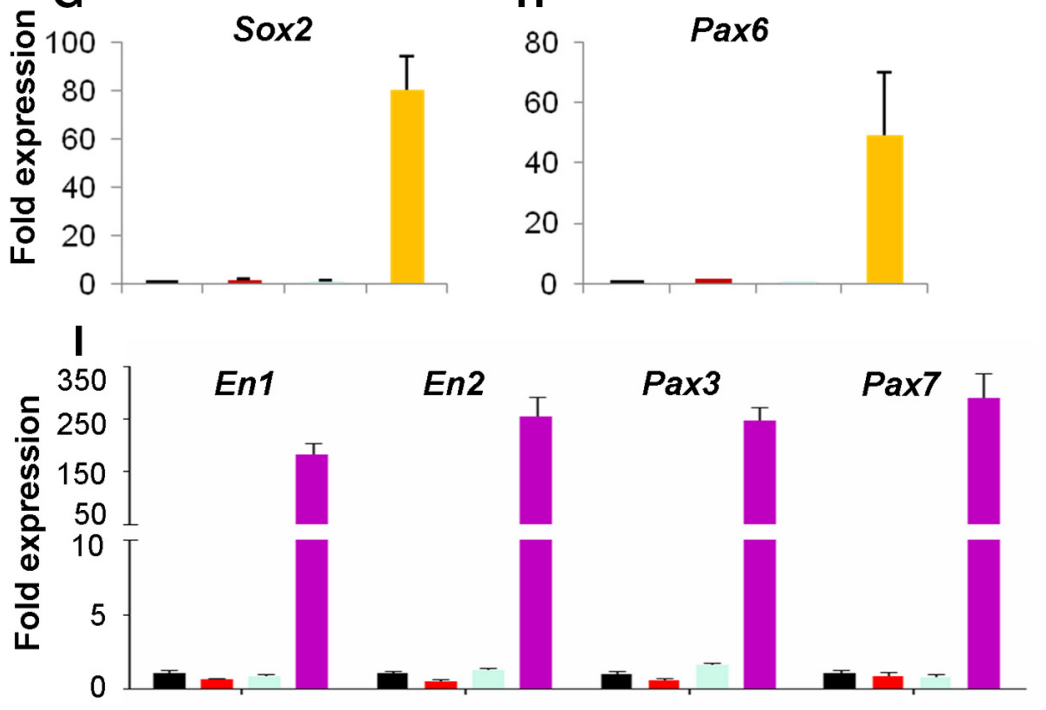

\section{D4 $\square$ D10 $\square$ D30 $\square$ Neurospheres $\square$ E12.5 midbrain}

Figure 6. Expression analysis of molecular markers of iN cells. $\boldsymbol{A}-\boldsymbol{H}$, mCherry ${ }^{+}$cells in the dorsal midbrain derived from WT mice that were infected with the virus AAV-Ascl1/mCherry at P12-P15 were collected by FACS on day 4 (D4, black bars), day 10 $(\boldsymbol{C})$, the neuronal markers Tuj1 (D), Map2 (E), and $\operatorname{NeuN}(\boldsymbol{F})$, the neural progenitor markers Sox2 $(\boldsymbol{G})$ and $\operatorname{Pax} 6(\boldsymbol{H})$, and the midbrain neural progenitor markers $E n 1, E n 2, P a x 3$, and $\operatorname{Pax} 7(\boldsymbol{I})$ was examined by qRT-PCR. The neurospheres (yellow bars) derived from the SVZ of mice at P0 were used as positive controls for detecting the expression of Sox2 and Pax6. The cells derived from E12.5 midbrain (purple bars) were used as positive controls for detecting the expression of En1, En2, Pax3, and Pax7.

cells infected with the control virus AAV-mCherry were all found in the astrocyte-like non-active category at all DPIs (Fig. $7 \mathrm{H}$, far left panel). In support of the notion that Ascl1-induced iN cells are fully matured by $30 \mathrm{DPI}$, we observed spontaneous postsynaptic currents in all recorded AAV-Ascl1/mCherry-infected cells ( $n=23$ of 23), and these synaptic events also appeared gradually within days after AAV infection (Fig. 7I). Additional pharmacological experiments suggested that the iN cells received both excitatory glutamatergic and inhibitory GABAergic synaptic inputs at $30 \mathrm{DPI}$ (Fig. 7J). Finally, these iN cells also made output synapses with existing neurons within the midbrain. As shown in Figure $7 K$, dual whole-cell recording showed that an iN cell $\left(\right.$ mCherry $^{+}$) made a GABAergic synaptic connection with a 

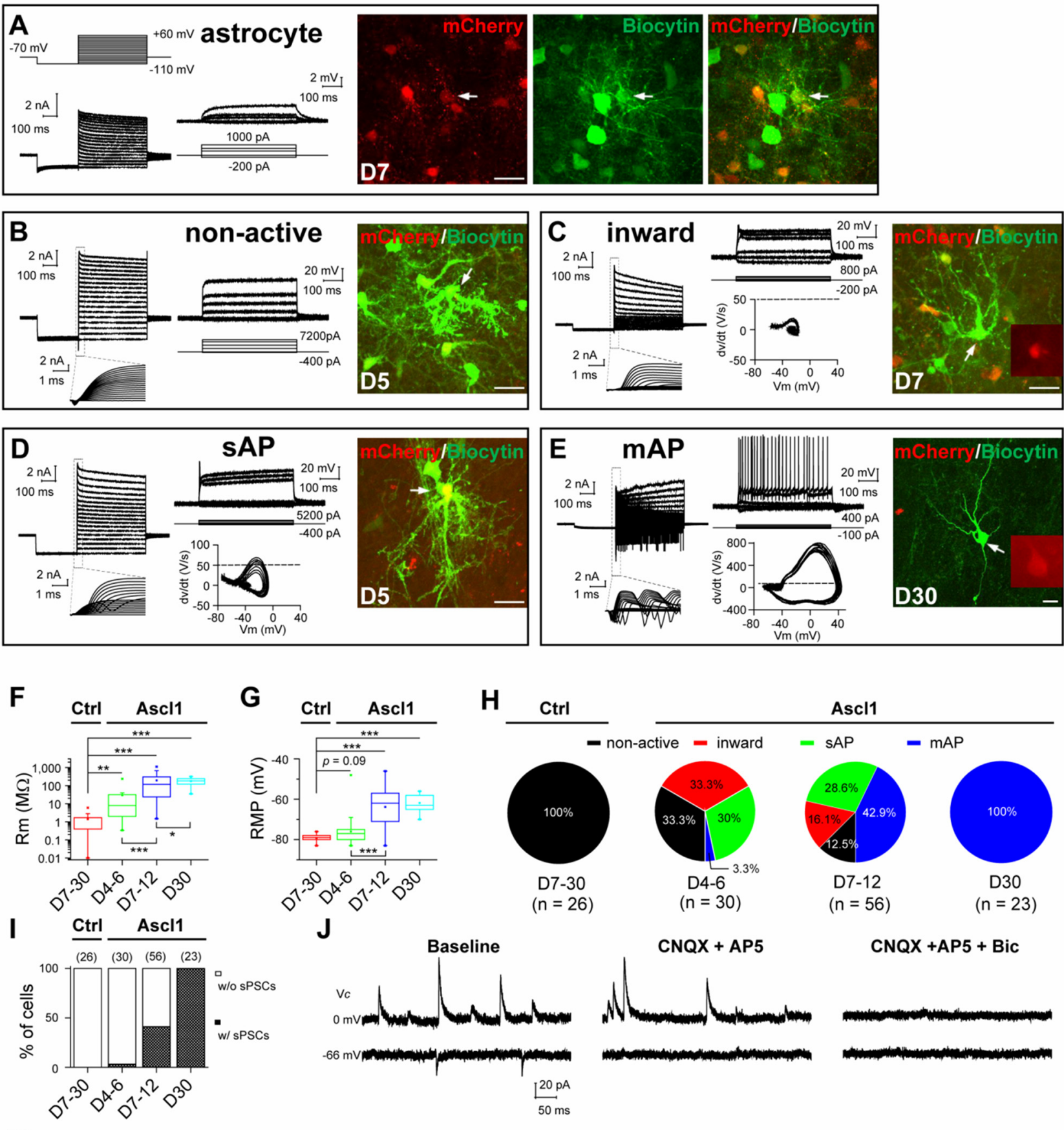

CNQX + AP5 + Bic
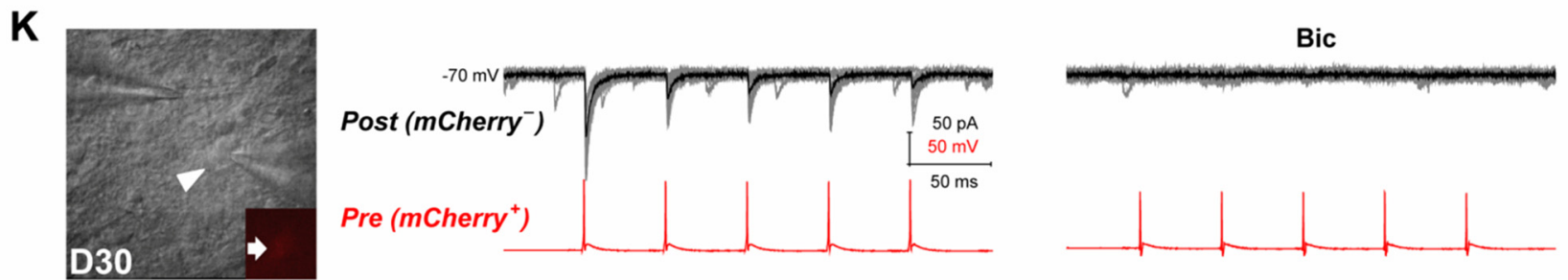

Figure 7. Functional characterization of iN cells generated in vivo. $A$, Membrane properties of an $\mathrm{mCherry}{ }^{+}$astrocyte recorded in an acute dorsal midbrain slice prepared from a WT mouse that was infected with the control virus AAV-mCherry at $7 \mathrm{DPI}$. Membrane currents (left) and voltages were recorded in voltage- and current-clamp modes, respectively, in responses to the step voltage or current commands. Fluorescence images from left to right: $m$ Cherry, biocytin staining, and superimposed fluorescence. Arrow, The cell recorded and filled with biocytin. Note the spread of biocytin to neighboring astrocytes, including several mCherry ${ }^{+}$cells. $\boldsymbol{B}-\boldsymbol{E}$, Membrane functions of iN cells (mCherry ${ }^{+}$) in slices of the dorsal midbrain that were prepared from WT mice infected with AAV-Ascl1/mCherry on day $5(\boldsymbol{B}, \boldsymbol{D})$, day $7(\boldsymbol{C})$, or day $30(\boldsymbol{E})$ after infection. Boxed regions, Membrane currents at a higher time resolution. Phase plots $\left(V_{\mathrm{m}} \mathrm{vs} \mathrm{dV} / \mathrm{dt}\right)$ of the initial $100 \mathrm{~ms}$ responses is used to detect the voltage threshold of the AP (indicated by dotted lines). The arrows in the fluorescence images (mCherry and biocytin staining) indicate the recorded cells. $\boldsymbol{F}, \mathbf{G}$, Membrane resistance $\left(R_{\mathrm{m}} ; \boldsymbol{F}\right)$ and RMP $(\boldsymbol{G})$ of astrocytes and iN cells over days after infection. $\boldsymbol{H}$, Percentages of induced cells with four different degrees of membrane excitability (non-active, inward, sAP, and $\mathrm{mAP}$ ) over days after infection with the control AAV-mCherry or AAV-AsC11/mCherry viruses. I, Percentages of induced cells showing sPSCs at different time points after infection with the control AAV-mCherry or AAV-Ascl1/mCherry viruses. J, Representative traces of spontaneous glutamatergic (inward) and GABAergic (outward) synaptic currents, (Figure legend continues.) 
neighboring tectal neuron $\left(\mathrm{mCherry}^{-}\right)$, as indicated by the evoked inhibitory synaptic currents in the mCherry ${ }^{-}$cell that could be abolished by bath application of bicuculline $(20 \mu \mathrm{M})$. Thus, iN cells converted directly from astrocytes in the dorsal midbrain could be integrated into existing neural circuits in vivo.

\section{In vivo conversion of dorsal midbrain astrocytes from adult mice into neurons by Ascl1}

To examine whether astrocytes from adult mice could be reprogrammed into neurons, we injected AAV-mCherry or AAVAscl1/mCherry into the dorsal midbrain of WT mice at P60. Double immunostaining showed that mCherry barely colocalized with NeuN in midbrain tissues infected with virus AAVmCherry ( $4.2 \pm 1.4 \%, n=3$ mice, $182-216$ cells per mice; Fig. $\left.8 A, A^{\prime}\right)$ or AAV-Ascl $1 /$ mCherry $(5.6 \pm 1.6 \%, n=3$ mice, $151-$ 335 cells per mice; Fig. $8 E, E^{\prime}$ ) at 5 DPI. At later time points, the vast majority of mCherry remained absent in $\mathrm{NeuN}^{+}$cells in control AAV-mCherry-infected tissues at $16 \mathrm{DPI}(6.7 \pm 3.6 \%$, $n=3$ mice, $236-312$ cells per mice; Fig. $\left.8 B, B^{\prime}\right)$ and at 38 DPI (3.7 $\pm 1.2 \%, n=3$ mice, $118-144$ cells per mice; Fig. $\left.8 C, C^{\prime}\right)$. Electrophysiological recordings from these mCherry ${ }^{+}$cells in control AAV-mCherry-infected mice showed that they had typical astrocytic properties in response to step voltage or current command (Fig. 8D). However, mCherry became progressively colocalized with NeuN in tissues infected by AAV-Ascl1/ mCherry, with the percentage of cells showing that colocalization increased to $63.5 \pm 3.1 \%$ ( $n=3$ mice, $131-266$ cells per mice $)$ at 16 DPI (Fig. $\left.8 F, F^{\prime}\right)$ and to $92.1 \pm 1.5 \%(n=3$ mice, $152-216$ cells per mice) at 38 DPI (Fig. $8 G, G^{\prime}$ ). We have also examined the transmitter phenotypes of the iN cells induced by Ascl 1 in adult mice and found that some iN cells expressed Gadl (11.7 $\pm 4.0 \%$, $n=3$ mice, $95-131$ cells per mice) or VGLUT2 $(6.3 \pm 1.3 \%, n=$ 3 mice, $97-105$ cells per mice) at $45 \mathrm{DPI}$, indicating the presence of both glutamatergic and GABAergic neurons in these iN cells. Additional whole-cell recordings from these mCherry ${ }^{+}$cells in brain slices prepared from AAV-Ascl1/mCherry-infected mice showed that a majority of recorded mCherry ${ }^{+}$cells (at 15-21 DPI, 9 of 10) had inward and outward currents in response to step voltage commands in voltage-clamp mode and fired APs in response to the injection of depolarizing step currents in current-clamp mode (Fig. 8H). Moreover, spontaneous postsynaptic currents were observed (in the voltage-clamp mode) in the majority of iN cells recorded (8 of 10 cells; Fig. 8I), suggesting that iN cells converted from astrocytes in adult mice could form functional synapses in vivo. Thus, Ascll could convert dorsal midbrain astrocytes into functional neurons in adult mice as well.

We have also made Cre-inducible AAV viruses, AAV-FLEXNLSGFP and AAV-FLEX-Ascl1/GFP, which contain FLEX switch sequence responsive to Cre in the AAV vector (Atasoy et al., 2008). These AAV viruses were injected into the dorsal midbrain of adult Aldh1l1-Cre transgenic mice. At day 28 after viral

\section{$\leftarrow$}

(Figure legend continued.) recorded at $V_{\text {clamp }}=-66$ and $0 \mathrm{mV}$, respectively, in an iN cell at 25 DPI. CNQX + AP-5 and bicuculline selectively blocked spontaneous glutamatergic and GABAergic events, respectively. $\boldsymbol{K}$, Recording of synaptic output from an induced GABAergic neuron onto one neighboring tectal neuron in the slice of a WT mouse at $30 \mathrm{DPI}$ of the virus AAV-Ascl1/mCherry. DIC image showed the simultaneous recordings on a presynaptic iN cell $\left(\mathrm{mCherry}{ }^{+}\right.$, arrow) and a postsynaptic $\left(\mathrm{mCherry}{ }^{-}\right)$neuron. Postsynaptic currents (at $V_{\text {clamp }}=$ $-70 \mathrm{mV}$ ) were elicited by a train of APs $(20 \mathrm{~Hz})$ in the presynaptic iN cell and completely blocked by bicuculline $(20 \mu \mathrm{M})$. Scale bars: $A-E, 20 \mu \mathrm{m}$. Ctrl, Control. ${ }^{*} p<0.05 ;{ }^{* *} p<0.01$; ${ }^{* * *} p<0.001$. Error bars indicate SEM. infection, although $\mathrm{GFP}^{+}$cells hardly expressed NeuN after infection of the control virus AAV-FLEX-NLSGFP $(2.9 \pm 1.1 \%$, $n=3$ mice, $121-181$ cells per mice; Fig. $8 J$ ), the majority of GFP ${ }^{+}$ cells turned on NeuN expression after infection of AAV-FLEXAscl1/GFP ( $90.1 \pm 2.1 \%, n=3$ mice, $126-170$ cells per mice; Fig. $8 K)$. Thus, Cre-dependent expression of Ascll could also convert astrocytes in the dorsal midbrain of adult mice into neurons.

To investigate whether converted iN cells have identical phenotypes to endogenous existing midbrain neurons, we further compared the electrophysiological properties between the endogenous neurons and iN cells induced in the dorsal midbrain. The midbrain tectal neurons in acute brain slices prepared from the WT (P42-P70) and Gad67-GFP (fluorescently labeled neurons, putative GABAergic; P51-P55) mice were examined by whole-cell recordings (Fig. 9A,B), and these WT neurons possessed membrane resistances of $489.1 \pm 131.1 \mathrm{M} \Omega(n=21$, WT $)$ and 326.0 $\pm 31.9 \mathrm{M} \Omega(n=17$, Gad67-GFP), as well as RMPs of $-57.6 \pm 2.0 \mathrm{mV}(n=19, \mathrm{WT})$ and $-57.1 \pm 1.9 \mathrm{mV}(n=15$, Gad67-GFP), respectively. The above values are similar to that of iN cells at 30 DPI induced in the young animals (resistance, $177.3 \pm 16.6, n=23$; RMPs, $-61.9 \pm 1.0, n=8$; Fig. $7 F, G$ ) and iN cells around 20 DPI induced in the adult mice (resistance, $240.0 \pm 81.9, n=9$; RMPs, $-61.0 \pm 1.2, n=6$ ). Moreover, based on their characteristic firing patterns, we classified these tectal neurons in WT mice into five major firing types (Fig. 9; Markram et al., 2004). We observed that firing phenotypes of the vast majority iN cells in both young and adult mice (P12-P15, 95.6\%, 22 of 23; P60, $100 \%, 9$ of 9) can be categorized into existing types observed in the normal midbrain neurons of WT and Gad67-GFP mice (Fig. 9C-E). In addition, some iN cells (P12-P15, 30-49 DPI, 82.6\%, 19 of 23; P60, 15-21 DPI, 77.8\%, 7 of 9) exhibited firing patterns identical to those of GABAergic neurons recorded in the midbrain of Gad67GFP mice, implicating their GABAergic identities. Together, these results suggest that iN cells induced in the midbrain exhibit similar membrane function phenotypes to the endogenous midbrain neurons, and the iN cells induced in the young (P12-P15) and adult (P60) animals have similar time course for functional maturation after the Ascll-induced conversion.

It has been shown that non-neuronal cells can be reprogrammed into neurons in the adult injured cortex, striatum, and spinal cord that were induced by stab wound or needle injection (Buffo et al., 2005; Grande et al., 2013; Guo et al., 2014; Su et al., 2014). In most of our above experiments involving stereotactic injection of AAV virus, we used injection micropipettes with diameters of $18-20 \mu \mathrm{m}$, and cells away from the injection sites were analyzed (Fig. 10A, inset). To determine whether micropipette injection induces an injured model similar to that induced by needle injection, we injected AAV viruses into the dorsal midbrain through micropipettes $(18-20 \mu \mathrm{m}$ in diameter) and 31 gauge needles $(\sim 260 \mu \mathrm{m}$ in diameter), respectively, and then performed immunostaining for mCherry and GFAP (a reactive astrogliosis marker) or a microglia marker IBA1 at 7 DPI. The results showed that the number of $\mathrm{GFAP}^{+}$reactive astrocytes around the injection site in mice injected with micropipettes was significantly less than that in mice injected with needles [micropipettes, $14.2 \pm 2.2$ cells, $n=3$ mice (Fig. 10A, $A^{\prime}$ ); needles, $113.6 \pm 15.7$ cells, $n=3$ mice (Fig. $\left.\left.10 C, C^{\prime}\right)\right]$. Moreover, the number of $\mathrm{IBA}^{+}{ }^{+}$microglia around the injection site in mice injected with micropipettes $(24.3 \pm 5.4$ cells, $n=3$ mice; Fig. $\left.10 B, B^{\prime}\right)$ was also pronouncedly less than that in mice injected with needles ( $74.3 \pm 12.0$ cells, $n=3$ mice; Fig. $\left.10 D, D^{\prime}\right)$. Similarly in the cortex, we also observed that the number of GFAP ${ }^{+}$or $\mathrm{IBA}^{+}{ }^{+}$glial cells in the needle injection condition (GFAP, $84.1 \pm$ 

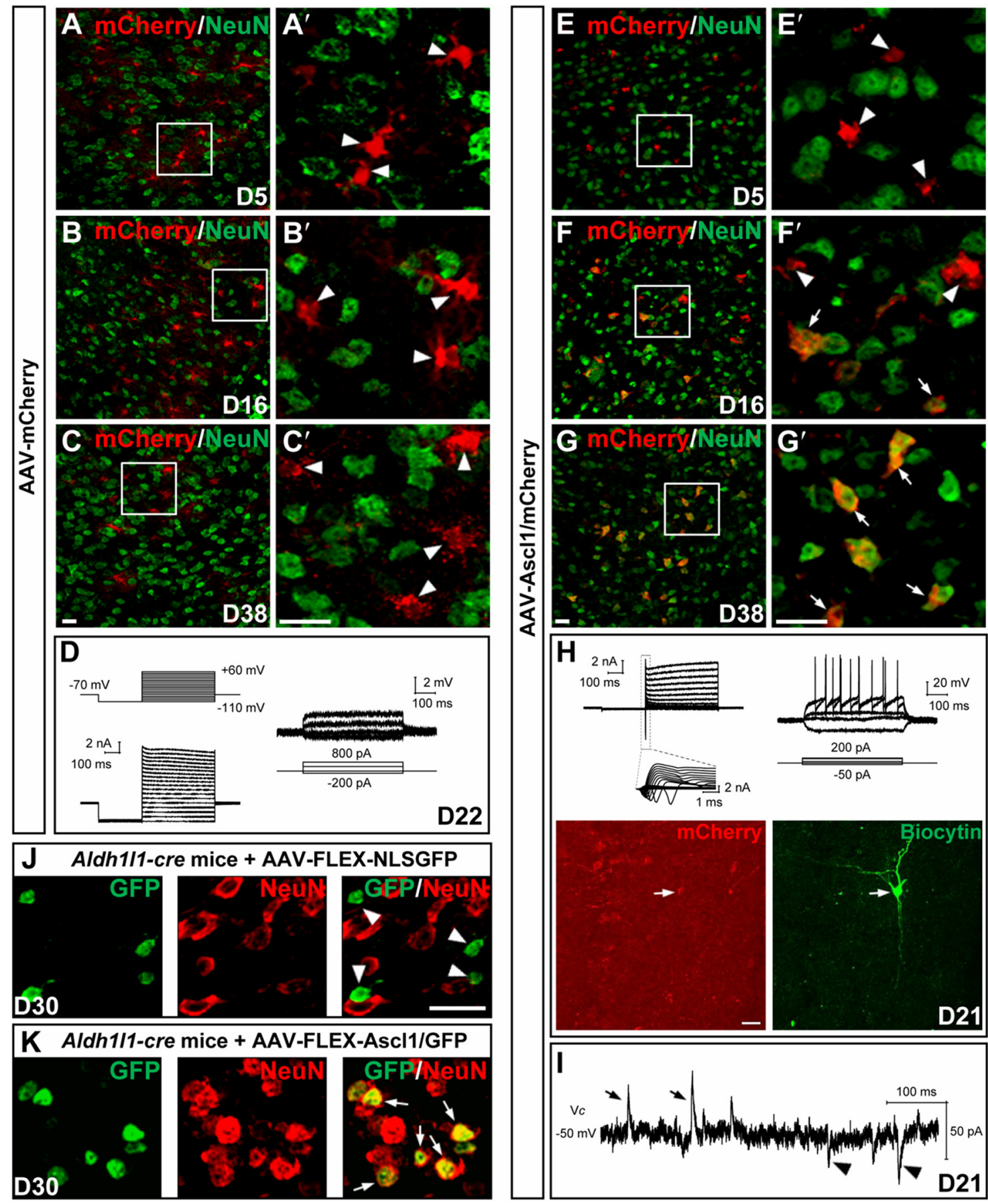

Figure 8. Conversion of dorsal midbrain astrocytes from adult mice into neurons by $A s c 11$ in vivo. $A-C^{\prime}$, Double staining of mCherry and NeuN on sections of the dorsal midbrain from adult mice that were infected with the control virus AAV-mCherry on day $5\left(\boldsymbol{A}, \boldsymbol{A}^{\prime}\right)$, day $16\left(\boldsymbol{B}, \boldsymbol{B}^{\prime}\right)$, and day $38\left(\boldsymbol{C}, \boldsymbol{C}^{\prime}\right)$. mCherry was not colocalized with NeuN (arrowheads). $\boldsymbol{A}^{\prime}, \boldsymbol{B}^{\prime}$, and $\boldsymbol{C}^{\prime}$ are higher magnification of the boxed areas in $A, B$, and $C$, respectively. $\boldsymbol{D}$, Membrane functions of a mCherry ${ }^{+}$astrocyte (22 DPI) recorded in an acute brain slice of the dorsal midbrain from an adult WT mouse infected with the control virus AAV-mCherry. Membrane currents (left) and voltages (right) were recorded in voltage- and current-clamp modes, respectively, in response to the step voltage or current commands. $\boldsymbol{E}-\boldsymbol{G}^{\prime}$, Double staining of $\mathrm{m} C$ herry and NeuN on sections of the dorsal midbrain from adult mice that were infected with the virus AAV-Ascl1/mCherry on day $5\left(\boldsymbol{E}, \boldsymbol{E}^{\prime}\right)$, day $16(\boldsymbol{F}$, $\left.\boldsymbol{F}^{\prime}\right)$, and day $38\left(\boldsymbol{G}, \boldsymbol{G}^{\prime}\right)$ after infection. mCherry was gradually colocalized with NeuN (arrows). $\boldsymbol{E}^{\prime}, \boldsymbol{F}^{\prime}$, and $\boldsymbol{G}^{\prime}$ are higher magnification of the boxed areas in $\boldsymbol{E}, \boldsymbol{F}$, and $\boldsymbol{G}$, respectively. $\boldsymbol{H}$, Membrane functions of an iN cell (mCherry ${ }^{+}$) in the slice of dorsal midbrain prepared from an adult WT mouse that was infected with AAV-Ascl1/mCherry at 21 DPI. The arrows in the fluorescence images ( $\mathrm{mCherry}$ and biocytin staining) indicate the recorded cell. $I$, Representative trace of spontaneous glutamatergic (inward) and GABAergic (outward) synaptic currents, recorded at $V_{\text {clamp }}=-50 \mathrm{mV}$ from an iN cell at 21 DPI. J, Double staining of GFP and NeuN on sections of the dorsal midbrain from adult Aldh1/1-Cre mice on day 30 after infection of the control virus AAV-FLEX-NLSGFP. GFP that was expressed in the nuclei did not colocalize with NeuN (arrowheads). $\boldsymbol{K}$, Double staining of GFP and NeuN on sections of the dorsal midbrain from adult Aldh $1 / 1-C r e$ mice on day 30 after infection of the virus AAV-FLEX-Ascl1/GFP. GFP that was expressed in the nuclei colocalized with NeuN (arrows). Scale bars, $20 \mu \mathrm{m}$.

12.1 cells; IBA1, $57.3 \pm 7.5$ cells; $n=3$ mice) was three to five times that in the micropipette injection condition (GFAP, $18.3 \pm$ 0.6 cells; IBA1, $18.4 \pm 2.9$ cells; $n=3$ mice; data not shown). These results indicated that AAV injection through 31 gauge nee- dles induced substantially larger injury to the brain tissue. Then we also examined whether astrocytes could be converted into neurons in the dorsal midbrain using the needle injection of AAV-mCherry or AAV-Ascl1/mCherry virus (also as the stab- 
A

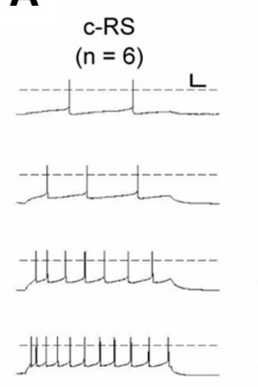

B
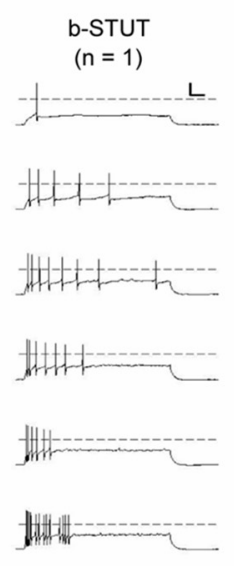

c-STUT

$(n=1)$

C
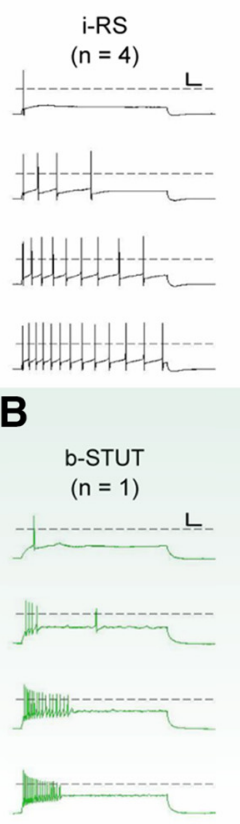

\section{i-RS}

$(n=3)$
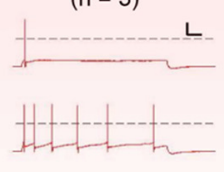

노-

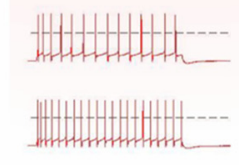

D

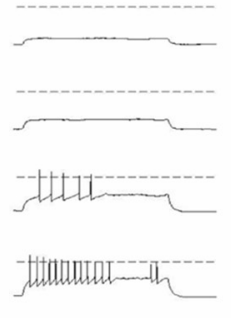

b-STUT

$(n=1)$
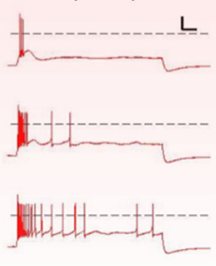

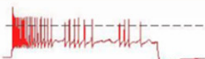

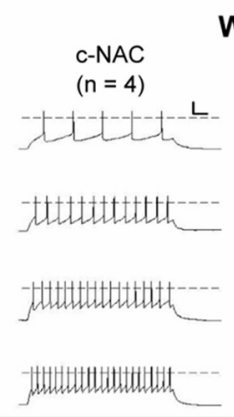

c-NAC

$(n=3)$
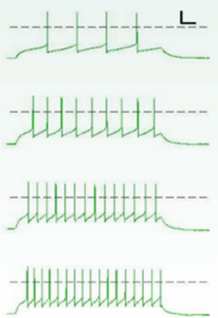

WT
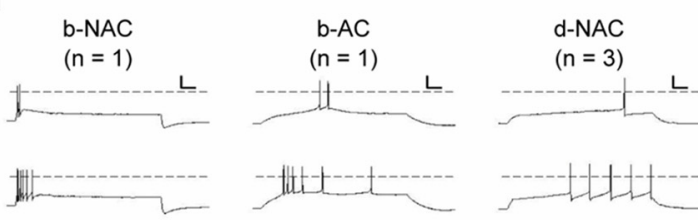

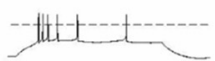
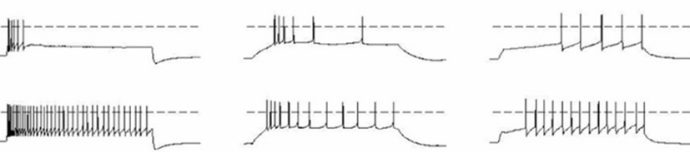

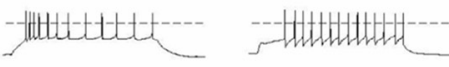

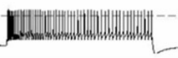

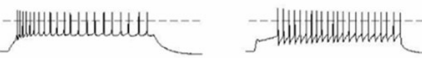

\section{Gad67-GFP}

b-NAC

$(n=8)$

b-AC

t-BST

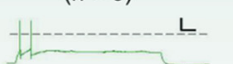

$(n=3)$

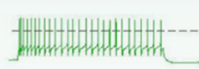

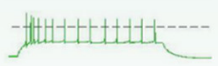

Hown

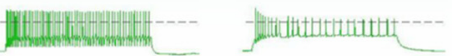

\section{iN cells (young animals)}

C-NAC

$(\mathrm{n}=9)$

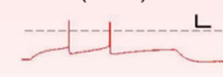

stettuttettin
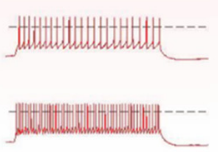

b-NAC

$(n=5)$

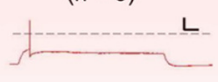

- Henthtettettutt--

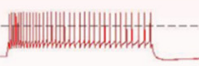

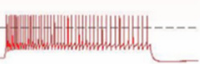

b-AC

$(n=5)$

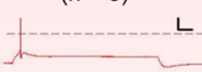

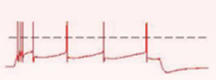

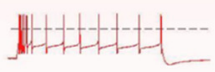

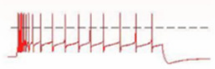

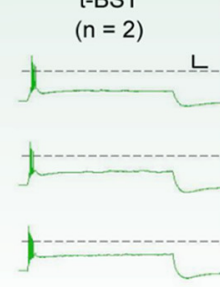

iN cells (adult animals)

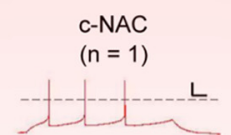

b-NAC

$(n=4)$
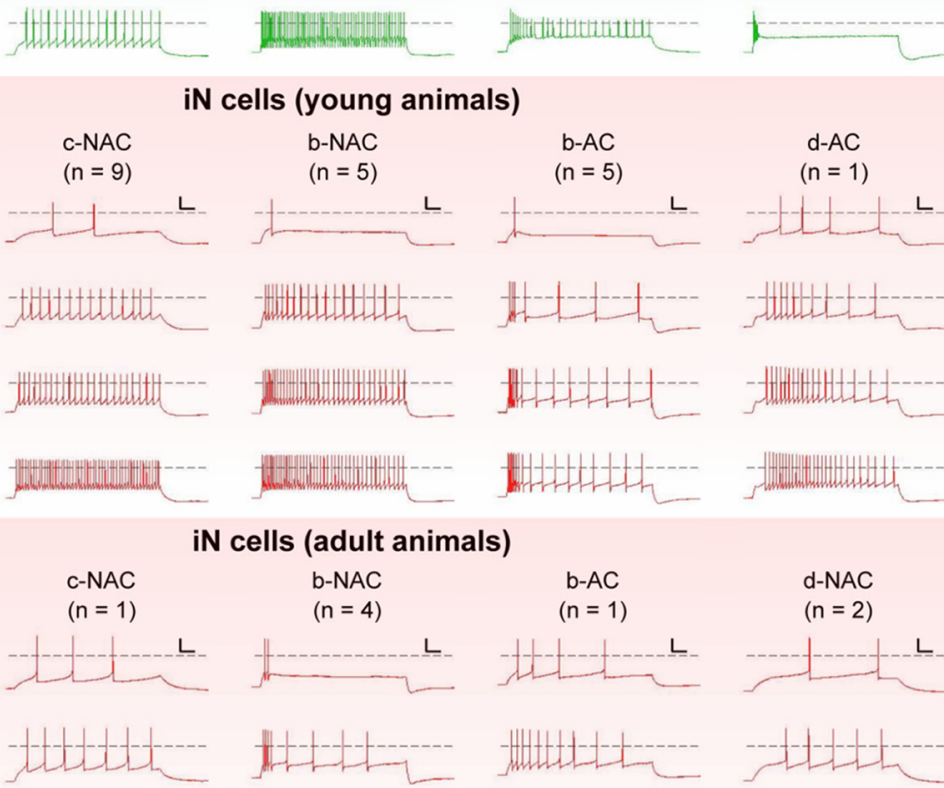

Htotitu

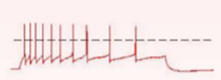

d-AC

$(\mathrm{n}=1)$

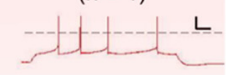

stuttet-tat-a

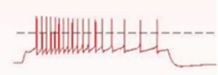

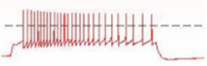
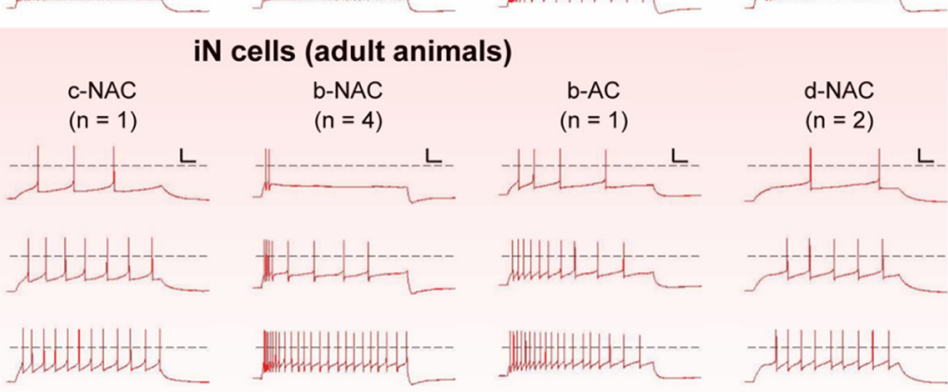

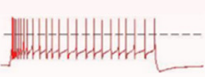

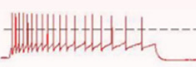

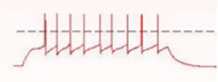

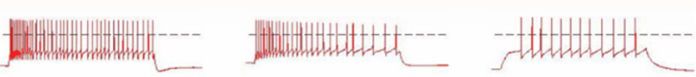

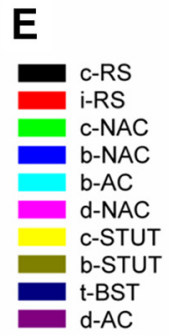

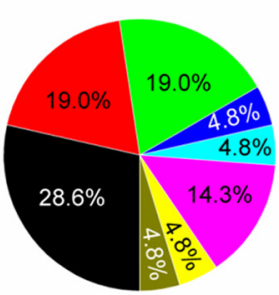

WT $(A)$

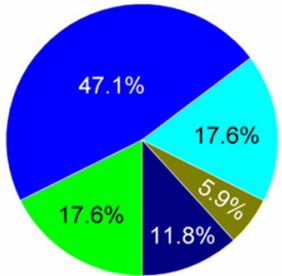

Gad67-GFP (B)

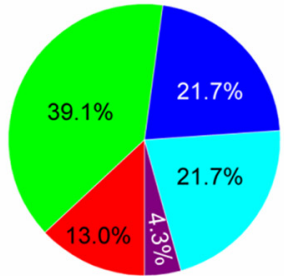

iN cells (C)

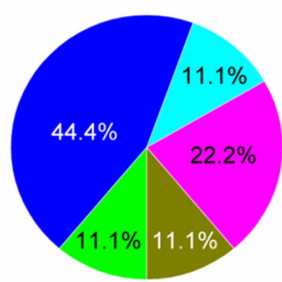

iN cells $(D)$

Figure 9. Firing patterns of WT neurons and in cells in the dorsal midbrain. Whole-cell recordings were performed on neurons in dorsal midbrain slices made from WT (A), Gad67-GFP (neurons expressing green fluorescence, putative GABAergic; $\boldsymbol{B}$ ), and AAV-Ascl1/mCherry-infected mice at P12-P15 (30 - 49 DPI; young; $\mathbf{C}$ or P60 (15-21 DPI; adult; D). Different categories of firing patterns of WT neurons were presented: classic regular-spiking (c-RS), instant regular-spiking (i-RS), classic non-accommodating (C-NAC), burst non-accommodating (b-NAC), delayed non-accommodating (D-NAC), accommodating (AC), classic stuttering (c-STUT), burst stuttering (b-STUT), and transient bursting (t-BST). Dash line denotes $0 \mathrm{mV}$. Calibration: $30 \mathrm{mV}, 50 \mathrm{~ms}$. E, Percentage of cells exhibiting different characteristic firing patterns recorded from neurons in WT mice (A), Gad67-GFP mice (B), and from iN cells induced in AAV-Ascl1/mCherry-infected mice at P12-P15 (C) or P60 (D). 


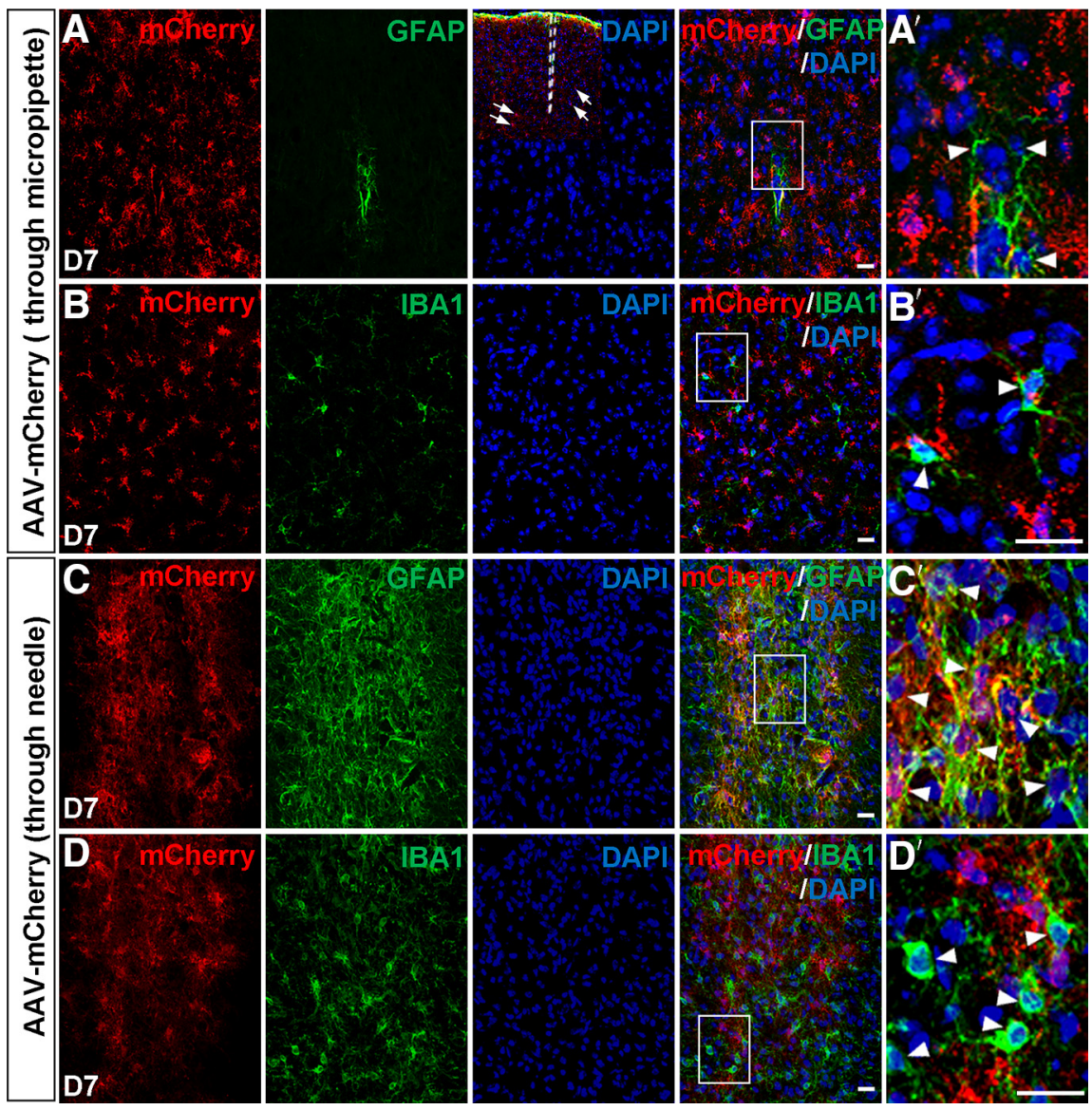

Figure 10. Injured states induced by micropipette or needle injections in the dorsal midbrain. $\boldsymbol{A}, \boldsymbol{B}$, Immunostaining of mCherry, GFAP $(\boldsymbol{A})$, or IBA1 $(\boldsymbol{B})$ on sections of the dorsal midbrain from adult mice that were infected with AAV-mCherry through micropipettes (18-20 $\mu \mathrm{m}$ in diameter) at $7 \mathrm{DPI}$. The inset in $\boldsymbol{A}$ shows that cells (arrows) away from the injection site were analyzed. $\boldsymbol{A}^{\prime}$ and $\boldsymbol{B}^{\prime}$ are higher magnification of the boxed areas in $\boldsymbol{A}$ and $\boldsymbol{B}$, respectively. $\boldsymbol{C}, \boldsymbol{D}$, Immunostaining of mCherry, GFAP $(\boldsymbol{C})$, or IBA1 (D) on sections of the dorsal midbrain from adult mice that were infected with AAV-mCherry by 31 gauge needles ( $\sim 260 \mu \mathrm{m}$ in diameter) at 7 DPI. $\boldsymbol{C}^{\prime}$ and $\boldsymbol{D}^{\prime}$ are higher magnification of the boxed areas in $\boldsymbol{C}$ and $\boldsymbol{D}$, respectively. Scale bars, $20 \mu \mathrm{m}$.

clamp mode (Fig. $11 F, G$ ) in response to the step electrical stimuli. In addition, sEPSCs and sIPSCs could be observed in all iN cells recorded (17 of 17 cells) (Fig. $11 \mathrm{H}$ ), suggesting that iN cells from injured midbrain astrocytes could have functional synapses. Together, these results showed that Ascl1 could convert astrocytes into functional neurons in adult injured midbrain.

\section{In vivo conversion of striatal and cortical astrocytes from adult mice into neurons by Ascl1}

To determine whether the conversion of astrocytes into neurons by Ascl1 is region specific, we examined whether astrocytes in the striatum and cortex of adult mice could be reprogrammed into neurons. We injected the virus AAV-mCherry or AAV-Ascl1/mCherry into the striatum of WT adult mice (P60). Double immunostaining showed that mCherry was barely expressed in neurons $\left(\mathrm{NeuN}^{+}\right)$, microglia $\left(\mathrm{IBA}^{+}{ }^{+}\right)$, oligodendrocytes $\left(\mathrm{Olig} 2^{+}\right)$, and $\mathrm{NG} 2$ cells $\left(\mathrm{NG}_{2}{ }^{+}\right.$; Fig. $\left.12 A-D, F\right)$. However, $\sim 96 \%$ of mCherry ${ }^{+}$cells expressed the astrocyte marker GS in the adult striatum (Fig. 12E,F). To determine the identity of mCherry $^{+}$cells after AAV viral infection, triple immunostaining of mCherry, GS, and NeuN was performed. The results showed that mCherry ${ }^{+}$cells expressed GS (Fig. 12G) $30 \mathrm{~d}$ after infection of the control AAV-mCherry virus. In contrast, most mCherry ${ }^{+}$cells lost the expression of GS but expressed $\mathrm{NeuN}$ $(64.4 \pm 3.4 \%, n=3$ mice, $119-129$ cells

wound injury condition). Double staining results showed that the majority of mCherry ${ }^{+}$cells $(92.8 \pm 1.2 \%, n=3$ mice, $60-117$ cells per mice) surrounding the needle injection site expressed GFAP in adult mice 3 DPI of the control virus AAV-mCherry (Fig. 11A). Thirty days after viral infection, mCherry remained hardly colocalized with $\mathrm{NeuN}$ in the control AAVmCherry-infected tissues $(2.5 \pm 1.2 \%, n=3$ mice, $78-82$ cells per mice; Fig. $11 B$ ). In contrast, many mCherry $^{+}$cells began to express $\mathrm{NeuN}$ in the injured dorsal midbrain infected by AAVAscl1/mCherry $(54.2 \pm 6.9 \%, n=3$ mice, $114-142$ cells per mice; Fig. $11 C$ ). We then investigated whether these iN cells have neuronal functions by performing whole-cell recordings in acute brain slices obtained from the AAV viruses infected mice. For $\mathrm{mCherry}^{+}$cells in mice infected with the control virus AAVmCherry (30 DPI), we found that they had a relatively small membrane resistance $(5.3 \pm 1.9 \mathrm{M} \Omega, n=6)$, more hyperpolarized membrane potentials $(-81.2 \pm 1.7 \mathrm{mV}, n=5$; Fig. $11 D)$, and no AP in response to intracellular injection of step depolarizing currents (Fig. 11E,G). However, whole-cell recordings from $\mathrm{mCherry}^{+}$cells in the AAV-Ascl1/mCherry-infected mice (30 DPI) revealed that these cells had a larger membrane resistance $(424.7 \pm 88.7 \mathrm{M} \Omega, n=17)$ and a more depolarized RMP $(-61.2 \pm 1.6 \mathrm{mV}, n=17$; Fig. $11 D)$, and all recorded mCherry ${ }^{+}$ cells (17 of 17) exhibited inward and outward currents in voltageclamp mode and fired repetitive APs (mAP, 17 of 17) in current- per mice; Fig. $12 \mathrm{H}$ ) after infection of the AAV-Ascl1/mCherry, indicating that the conversion from astrocyte to neuron occurred.

To further examine whether these iN cells are functional, we performed whole-cell recordings in acute brain slices obtained from the infected mice. The induced cells were identified by the presence of red fluorescence. In slices from mice infected with the control virus AAV-mCherry (30 DPI), we found that infected cells exhibited a relatively small membrane resistance $(2.9 \pm 1.0$ $\mathrm{M} \Omega, n=7)$, a more hyperpolarized $\mathrm{RMP}(-79.0 \pm 0.3 \mathrm{mV}, n=$ 7; Fig. 12I), and no AP in response to intracellular injection of step currents (Fig. 12J,L). These properties were quantitatively and qualitatively comparable with those of astrocytes (Volterra and Meldolesi, 2005). Whole-cell recordings from mCherry ${ }^{+}$ cells in the AAV-Ascl1/mCherry-infected mice (30 DPI) showed that a majority of recorded mCherry ${ }^{+}$cells ( 15 of 16$)$ had inward and outward currents in voltage-clamp mode and could fire APs (13 of 16) in the current-clamp mode (Fig. $12 \mathrm{~K}, \mathrm{~L}$ ). Moreover, sEPSCs and sIPSCs were also observed in the majority of iN cells recorded (12 of 16 cells; Fig. 12M). Together, these results demonstrate that Ascl 1 could convert striatum astrocytes into functional neurons in adult mice.

We also examined whether Ascl1 could convert cortical astrocytes into neurons in vivo. We injected the virus AAV-mCherry or AAV-Ascll/mCherry into the somatosensory cortex of WT 

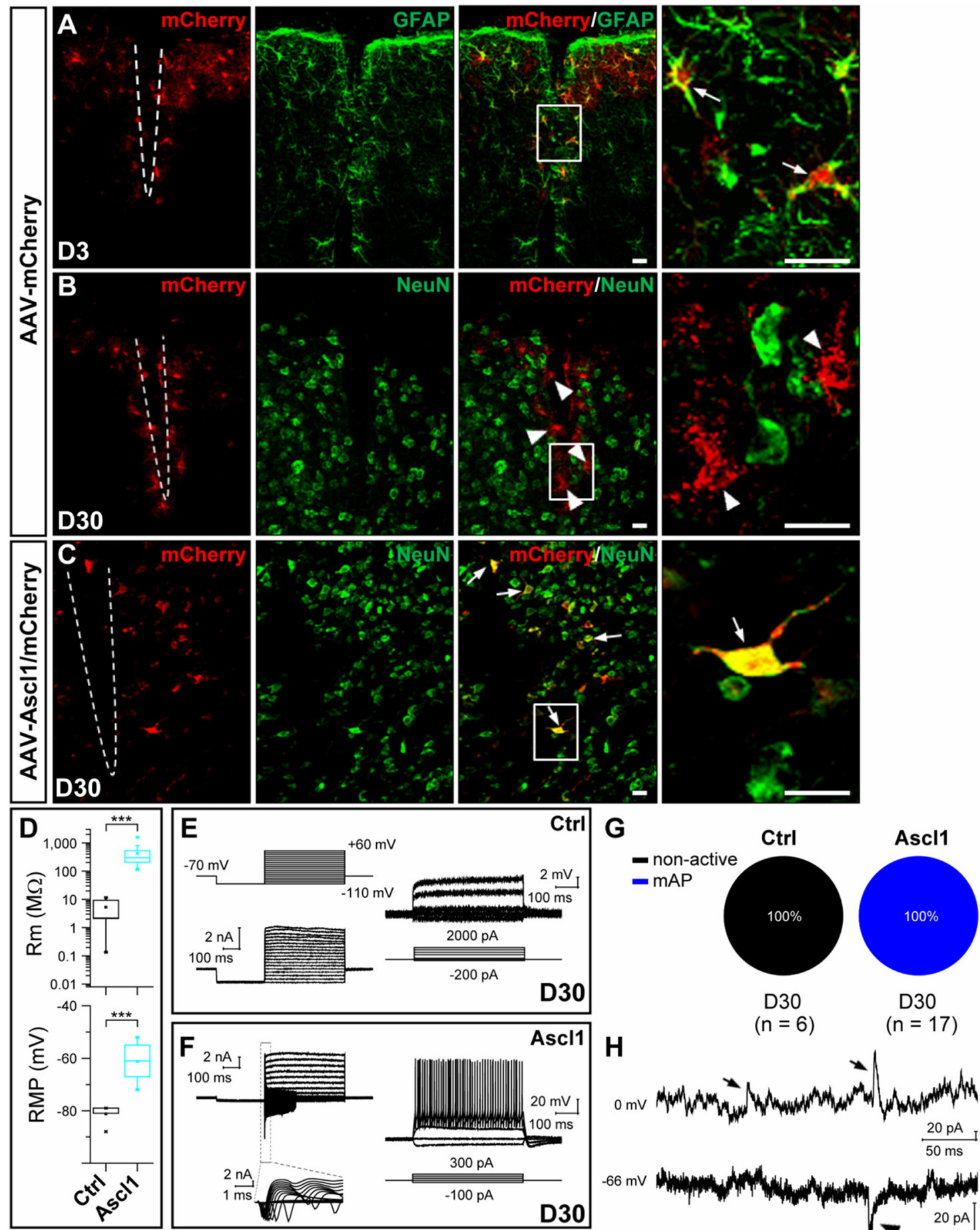

Figure 11. Conversion of reactive astrocytes into neurons by Ascl1. A, Double staining of mCherry and GFAP on sections of the injured dorsal midbrain from adult mice that were infected with the control virus AAV-mCherry $(\boldsymbol{A})$ at 3 DPI. Most $m$ Cherry ${ }^{+}$cells expressed GFAP in the injured site. $B, C$, Double staining of $m$ Cherry and NeuN on sections of the injured dorsal midbrain from adult mice that were infected with the control AAV-mCherry $(\boldsymbol{B})$ or AAV-Ascl1/mCherry $(\boldsymbol{C})$ virus at $30 \mathrm{DPI} . \boldsymbol{D}, R_{\mathrm{m}}$ and RMP of induced cells of the injured dorsal midbrain in mice $30 \mathrm{~d}$ after infection of the control AAV-mCherry or AAV-Ascl1/mCherry virus. E, $F$, Membrane currents (left) and voltages (right), elicited by step voltage and current commands, respectively, of an example $m$ Cherry ${ }^{+}$cell in the slice of injured dorsal midbrain from a WT mouse $30 \mathrm{~d}$ after infection of the control virus AAV-mCherry (E) or an example iN cell (mCherry ${ }^{+}$) in the slice of dorsal midbrain from a WT mouse $30 \mathrm{~d}$ after the infection of the AAV—Ascl1/mCherry virus $(\boldsymbol{F})$. G, Percentages of induced cells with different degrees of membrane excitability (non-active and $\mathrm{mAP}$ ) in mice $30 \mathrm{~d}$ after infection of the control AAV-mCherry or AAV-Ascl1/mCherry virus. $\boldsymbol{H}$, Representative spontaneous inward (putative glutamatergic, arrowhead) and outward (putative GABAergic, arrow) synaptic currents recorded at $V_{\text {clamp }}=-66$ and $0 \mathrm{mV}$, respectively, from an iN cell at $30 \mathrm{DPI}$. Scale bars, $20 \mu \mathrm{m}$. Ctrl, Control. Kolmogorov-Smirnov test was used in $\boldsymbol{D} .{ }^{* * *} p<0.001$. Error bars indicate SEM.

adult mice (P60). Double immunostaining showed that mCherry was barely colabeled with NeuN $(2.6 \pm 0.8 \%, n=3$ mice, 120 133 cells per mice; Fig. 13A) in the cortex $30 \mathrm{~d}$ after infection of the control virus AAV-mCherry. In contrast, the vast majority mCherry ${ }^{+}$cells expressed NeuN in the cortex $30 \mathrm{~d}$ after infection of the virus AAV-Ascl1/mCherry $(93.9 \pm 1.2 \%, n=3$ mice, 132-147 cells per mice; Fig. 13B). In slices from mice infected with the control virus AAV-mCherry (30 DPI), whole-cell recording showed that infected cells still exhibited membrane properties similar to that of astrocytes (membrane resistance, 

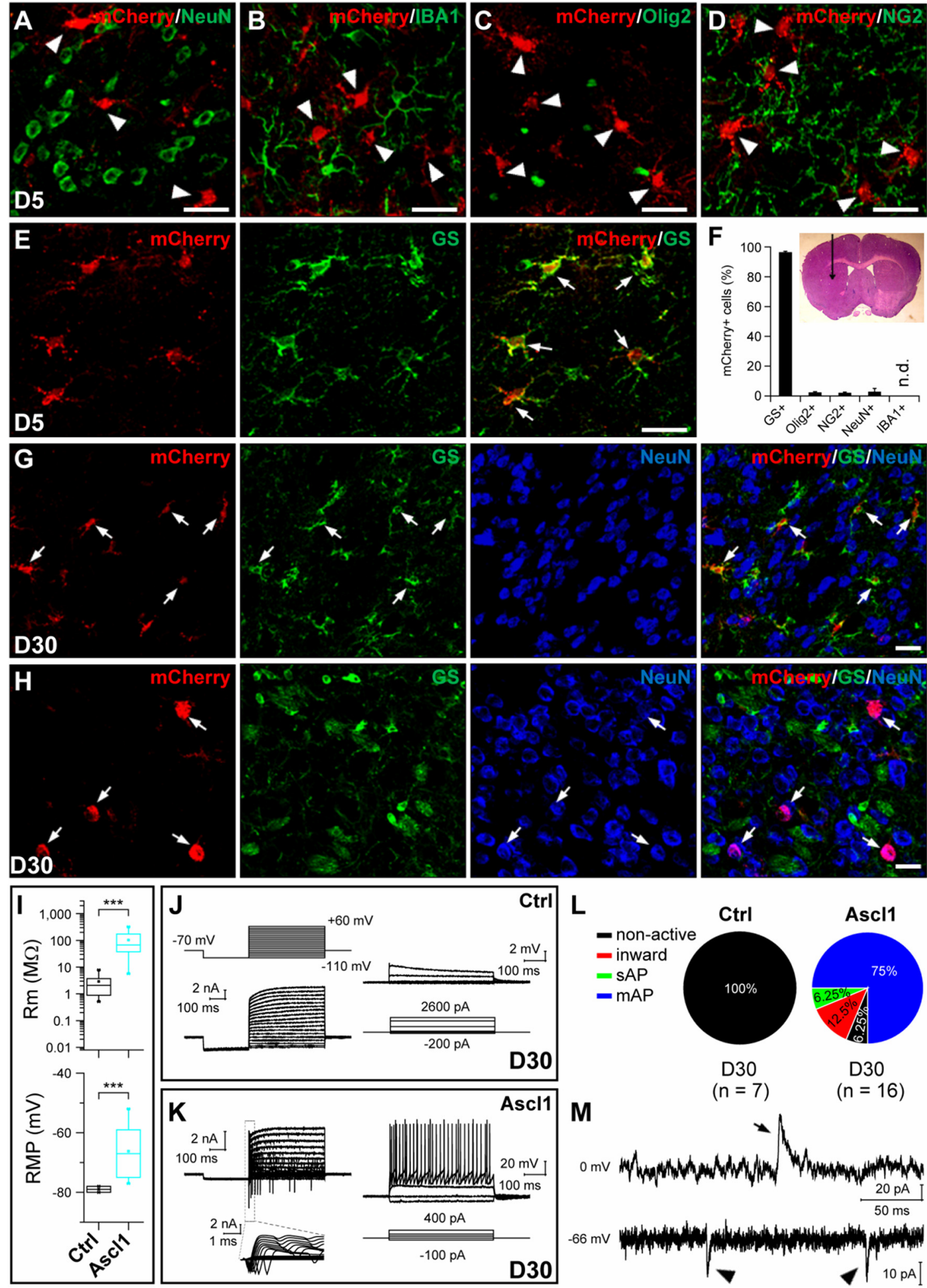

Ascl1

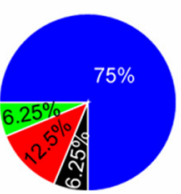

$\mathrm{D} 30$
$(\mathrm{n}=7)$

D30

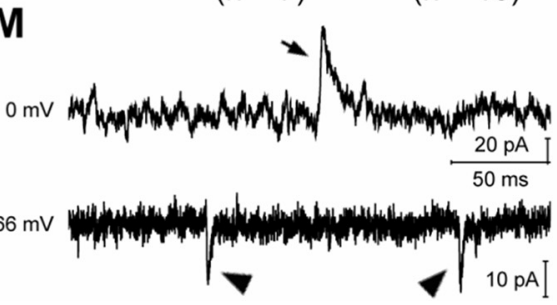

Figure 12. Conversion of striatal astrocytes from adult mice into neurons by Ascl1 in vivo. $A-F$, Double staining of $m$ Cherry and NeuN $(\boldsymbol{A}), \operatorname{lBA1}(\boldsymbol{B}), 0$ lig2 (C), NG2 (D), or GS (E) on sections of the striatum from WT adult mice infected with the control virus AAV-mCherry at $5 \mathrm{DPI}$. mCherry was almost exclusively expressed in $\mathrm{GS}^{+}$astrocytes but not other cell types $(\boldsymbol{F})$. The inset shows the area in which the AAV viruses were injected. $\boldsymbol{G}, \boldsymbol{H}$, Triple staining of $\mathrm{mCherry}, \mathrm{GS}$, and NeuN on sections of the striatum from adult mice that were infected with the control virus AAV-mCherry (G) or with virus AAV-Ascl1/mCherry at $30 \mathrm{DPI}(\boldsymbol{H}) . \boldsymbol{I}, R_{\mathrm{m}}$ and RMP of induced cells on $30 \mathrm{DPl}$ of the control AAV-mCherry or AAV-Ascl1/mCherry virus.J, $\boldsymbol{K}$, Membrane currents (left) and voltages (right) elicited by step voltage and current commands, respectively, of an example mCherry ${ }^{+}$cell in the striatal slice from a WT mouse $30 \mathrm{~d}$ after infection of the control virus AAV-mCherry $(\boldsymbol{)})$ or an example iN cell ( $\mathrm{mCherry}{ }^{+}$) in the striatal slice from a WT mouse $30 \mathrm{~d}$ after infection of the AAV-Ascl1/mCherry virus (K). L, Percentages of induced cells with four different degrees of membrane excitability (non-active, inward, sAP, and mAP) in mice $30 \mathrm{~d}$ after infection of the control AAV-mCherry or AAV-Asc11/mCherry virus. M, Representative traces of spontaneous inward (putative glutamatergic, arrowhead) and outward (putative GABAergic, arrow) synaptic currents, recorded at $V_{\text {clamp }}=-66$ and $0 \mathrm{mV}$, respectively, from an iN cell at $30 \mathrm{DPI}$. Scale bars, $20 \mu \mathrm{m}$. Ctrl, Control. Kolmogorov-Smirnov test was used for Rm and RMP in $I$. ${ }^{* * *} p<0.001$. Error bars indicate SEM. 

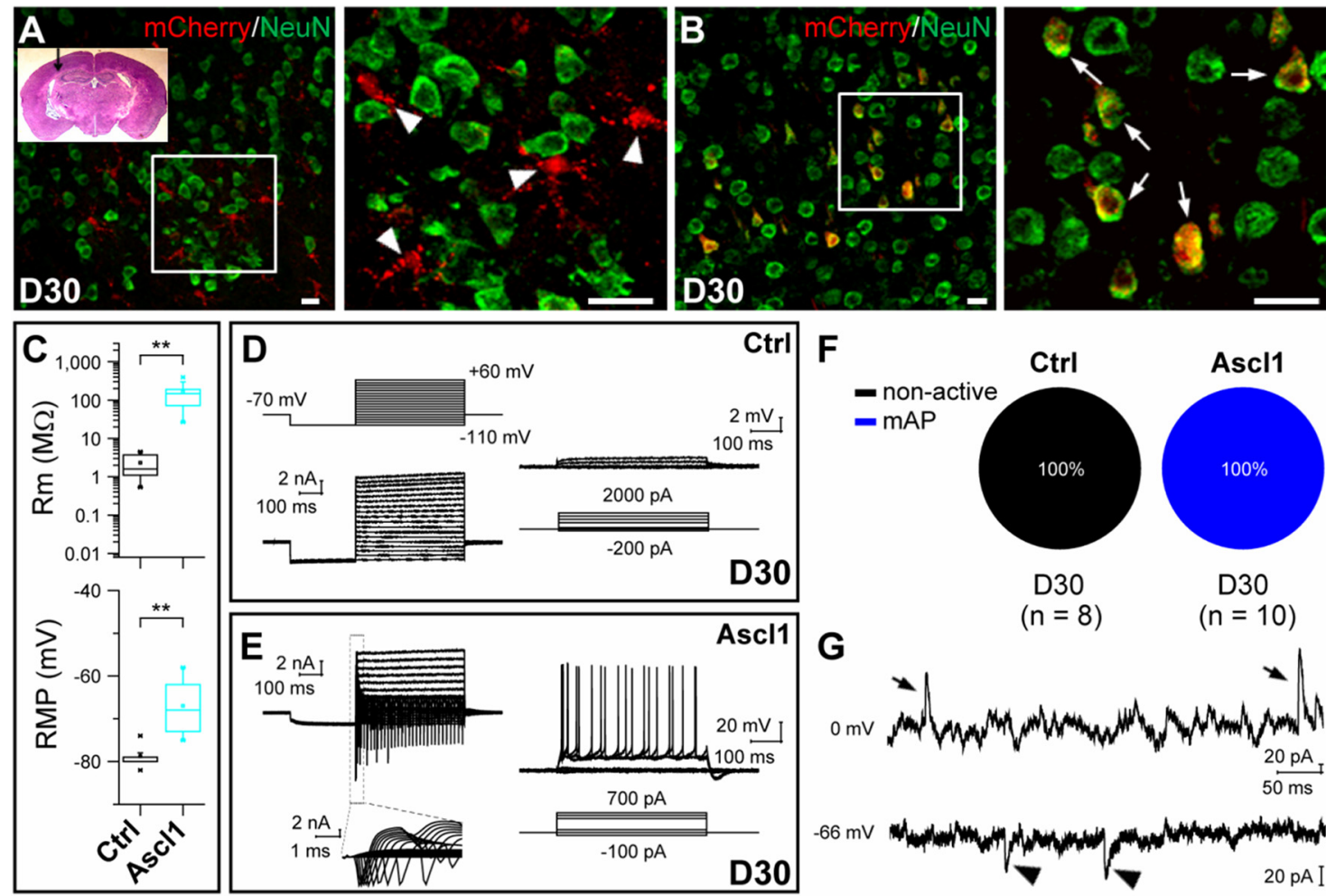

Figure 13. Conversion of cortical astrocytes from adult mice into neurons by $A s c 11$ in vivo. $A, B$, Double staining of $m$ Cherry and NeuN on sections of the cortex from adult mice that were infected with the control virus AAV-mCherry $(\boldsymbol{A})$ or with virus AAV-Ascl1/mCherry $(\boldsymbol{B})$ at $30 \mathrm{DPI}$. The inset shows the area in which the AAV viruses were injected. $\boldsymbol{C}, R_{\mathrm{m}}$ and RMP of induced cells in mice $30 \mathrm{~d}$ after infection of the control AAV-mCherry or AAV-Ascl1/mCherry virus. D, E, Membrane currents (left) and voltages (right) elicited by step voltage and current commands, respectively, of an example $\mathrm{mCherry}{ }^{+}$cell in the slice of somatosensory cortex from a WT mouse $30 \mathrm{~d}$ after infection of the control virus AAV-mCherry $(\boldsymbol{D})$ or an example iN cell (mCherry ${ }^{+}$) in the slice of somatosensory cortex from a WT mouse $30 \mathrm{~d}$ after infection of the AAV-Ascl1/mCherry virus $(\boldsymbol{E})$. $\boldsymbol{F}$, Percentages of induced cells with different degrees of membrane excitability (non-active and $\mathrm{mAP}$ ) in mice $30 \mathrm{~d}$ after infection of the control AAV-mCherry or AAV-Ascl1/mCherry virus. G, Representative traces of spontaneous inward (putative glutamatergic, arrowhead) and outward (putative GABAergic, arrow) synaptic currents, recorded at $V_{\text {clamp }}=-66$ and $0 \mathrm{mV}$, respectively, from an iN cell at 30 DPI. Scale bars, $20 \mu \mathrm{m}$. Ctrl, Control. Student's t test and Kolmogorov-Smirnov test were used for Rm and RMP in C, respectively. ${ }^{* *} p<0.01$. Error bars indicate SEM.

$2.3 \pm 0.5 \mathrm{M} \Omega, n=8 ; \mathrm{RMP},-78.8 \pm 0.8 \mathrm{mV}, n=7$, Fig. $13 C$; no APs, Fig. $13 D, F)$. In contrast, the mCherry ${ }^{+}$cells in the AAVAscl1/mCherry-infected mice (30 DPI) showed a larger membrane resistance $(163.3 \pm 35.9 \mathrm{M} \Omega, n=10)$, more depolarized resting potential $(-67 \pm 2.2 \mathrm{mV}, n=8$; Fig. $13 C)$, and inward and outward currents or APs in all recorded 10 cells (Fig. 13E,F). Again, sEPSCs and sIPSCs could be observed in these 10 cells (Fig. $13 G$ ). In conclusion, these results suggested that Ascl1 could convert neocortical astrocytes into functional neurons in adult mice.

\section{Discussion}

In this study, we first found that a single transcription factor, Ascl1, could convert astrocytes from mouse dorsal midbrain into neurons efficiently in vitro. Taking advantage of the astrocyte specificity of the GFAP promoter, we then showed that AAV driven by the GFAP promoter could specifically target astrocytes in the dorsal midbrain and AAV-Ascl1 could efficiently convert astrocytes in the dorsal midbrain, striatum, and somatosensory cortex into neurons in vivo. The iN cells generated in vivo exhibited neuronal morphology, could fire APs, received synaptic inputs, and made output synapses to preexisting neurons.

\section{Ascl1 converts cultured astrocytes into functional neurons}

Together with other transcription factors, Ascl1 has been used in generating iN cells from fibroblasts, hepatocytes, and pericytes in vitro (Vierbuchen et al., 2010; Caiazzo et al., 2011; Kim et al., 2011; Marro et al., 2011; Pfisterer et al., 2011; Son et al., 2011;
Karow et al., 2012). It has also been used to reprogram postnatal cortical astrocytes into neurons in vitro, as indicated by the expression of Tuj1 and the ability to fire APs in the cells infected with the retroviral vector expressing Ascl1 alone in vitro (Berninger et al., 2007b), although whether these iN cells were able to form synapses and the nature of the neuronal type were unclear. In the current study, we examined the role of Ascll in reprogramming using astrocytes isolated from a brain area (the dorsal midbrain) that is known to require Ascl1 for GABAergic neuronal differentiation during development (Peltopuro et al., 2010). The majority of cells in the astrocyte preparations expressed the astrocyte markers GFAP and $S 100 \beta$, whereas markers for other cell types were not or rarely detected (data not shown). We found that Ascl1 alone could efficiently convert astrocytes from the postnatal dorsal midbrain into neurons in vitro and these iN cells could form functional synapses (Fig. $1 A-G$ ). The finding is in line with a recent study that showed that $A s c l 1$ is able to convert fibroblasts into iN cells when the cells are cultured in optimized conditions (Chanda et al., 2014). Furthermore, the iN cells induced by Ascll expressed molecular markers for glutamatergic and GABAergic neurons and are presynaptically competent for secreting the neurotransmitters glutamate and GABA (Fig. $1 H, I$ ).

Ascl1 converts astrocytes into functional neurons in vivo To demonstrate that expression of Ascll alone is capable of converting astrocytes into neurons in vivo, we have focused on the dorsal midbrain and used multiple approaches to verify that the 
identity of the cell type being converted is astrocyte. First, we found that AAV vectors driven by the GFAP promoter target astrocytes specifically in WT mice (Fig. 2A,B). Second, we used two astrocyte-specific reporter mouse lines (Aldh1l1-GFP and GFAP-GFP) to confirm the astrocyte specificity of the GFAPAAV vectors (Fig. $2 C, D$ ). Third, by analyzing the GFAP-CreERT2;Rosa26-CAG-tdTomato mice, we found that $\mathrm{GFAP}^{+}$cells found at P12-P14 are indeed astrocytes, not neurons or neuronal progenitors (Fig. 2E and data not shown). Fourth, we found that Cre-dependent expression of Ascl1 converts astrocytes into neurons (Fig. $8 \mathrm{~J}, \mathrm{~K}$ ).

We have examined the reprogramming of astrocytes at early postnatal (P12-P15) and young adult stages. We found that Ascl1 converts astrocytes into neurons with relatively high efficiencies at these two stages: $93.1 \%$ and $92.1 \%$ of astrocytes at P12-P15 (Fig. $3 F$ ) and at P60 (Fig. $8 G$ ), respectively. Meanwhile, almost all of the iN cells induced at both stages exhibits distinct firing patterns that are identical to that of endogenous WT midbrain neurons (Fig. 9). Furthermore, the iN cells induced at the two stages express glutamatergic and GABAergic transmitter phenotypes (Fig. 3G, $H$ and data not shown). Because astrocytes are highly heterogeneous among different brain areas, we also examined the reprogramming of astrocytes in the adult striatum and cortex, in addition to the dorsal midbrain. Interestingly, our results show that Ascl1 converts cortical astrocytes into neurons efficiently (93.9\%; Fig. 13B), but it has relatively less efficiency in the striatum (64.4\%; Fig. 12H). The reason for the varied efficiency of astrocyteto-neuron conversion in different anatomical locations is unknown. Conversely, a recent study showed that overexpression of Ascl by retroviruses failed to induce neurogenesis in the injured striatum and neocortex of adult rats (Grande et al., 2013). The discrepancy between the previous report and our present work could be attributed to the differences in species, vector viruses, and injury conditions used in these studies.

The efficiency of conversion of non-neuronal cells into iN cells varies substantially with different starting cell types (Ang and Wernig, 2014; Mirakhori et al., 2014): (1) immature cells are reprogrammed with higher efficiency than those obtained in more developed donors; (2) human cells are usually more resistant to iN cell reprogramming than their mouse counterparts; and (3) closely related cell types have higher efficiency in cell type conversion. The efficient astrocyte-to-neuron conversion showed in this study will be helpful in optimizing iN cell reprogramming in vivo.

Previous studies have revealed two distinct pathways for the conversion of non-neuronal cells into neurons (Vierbuchen et al., 2010; Niu et al., 2013): one is through the stage of neural stem/progenitor cells, and the other is direct conversion from non-neuronal cells into neurons. We have provided several pieces of evidence to show the $A s c l 1$ induces astrocyte-to-neuron conversion perhaps via a direct transdifferentiation. First, neurospheres could not be generated from the dorsal midbrain at P12 (Fig. 3I). Second, iN cells were not generated from endogenous NSCs (Fig. 3L). Third, expression of neuronal progenitor markers could not be detected during the conversion (Fig. $6 G-I$ ). Last, Ascll-induced astrocyte-to-neuron conversion does not pass through a proliferative state (Fig. 4).

In this study, we found that Ascll overexpression in the dorsal midbrain does not induce significant oligoneogenesis, as indicated by the expression of oligodendrocyte markers GST- $\pi$ and Olig2 (Fig. 5). This is different from the reports that Ascll overexpression generates oligodendrocytes in the adult spinal cord and dentate gyrus (Ohori et al., 2006; Jessberger et al., 2008), respectively. It is noteworthy that, in these studies, Ascll was overexpressed in the neural progenitor cells of injured spinal cord and adult hippocampal stem/progenitors. Furthermore, most of the generated oligodendrocytes following the overexpression of Ascll in the spinal cord are immature, and the Ascll overexpression may direct oligodendrocytic fate only in the subgranular zone (SGZ) but not the SVZ. It is also of note that Ascl1 proved insufficient to induce oligodendrocytic fate by isolated SGZ progenitors, indicating a context-dependent effect of Ascll in oligoneogenesis.

Ascl1 is expressed predominantly by neural progenitor cells in the ventral telencephalon and is required for the production of GABAergic neurons (Casarosa et al., 1999; Horton et al., 1999). Although Ascl1 acts as a pioneer factor in generating iN cells (Wapinski et al., 2013), the neuronal phenotypes differ when different combinations of transcription factors are used in culture. The majority of iN cells induced from fibroblasts by three transcription factors, Ascl1, Brn2, and Mytll or Ascl1, alone are glutamatergic neurons (Vierbuchen et al., 2010; Chanda et al., 2014). However, a combination of Ascl1 and Sox2 appears to favor the conversion of pericytes into GABAergic phenotypes (Karow et al., 2012). Ascll is also used in inducing dopaminergic neurons and motor neurons (Caiazzo et al., 2011; Kim et al., 2011; Pfisterer et al., 2011; Son et al., 2011). We have observed that both glutamatergic and GABAergic neurons existed in the Ascl1-induced iN cells (Figs. 1H, I, 3G,H; data not shown). The simultaneous generation of both excitatory and inhibitory neurons by Ascl 1 could be useful for the balance of excitation and inhibition in the dorsal midbrain. To obtain iN cells with a specific transmitter phenotype, more transcription factors may need to be included. Besides Ascl1, other two transcription factors, Helt and Gata2, are required for proper differentiation of GABAergic neurons in the dorsal midbrain during development (Guimera et al., 2006; Kala et al., 2009). It is possible that Helt and/or Gata2 are required to generate a high percentage of GABAergic neurons in vivo.

Among various viral systems available for therapeutic gene delivery to the CNS, AAV is currently the most appropriate vector (Lentz et al., 2012). Astrocytes are distributed ubiquitously in the CNS (Hewett, 2009; Zhang and Barres, 2010). With additional understanding of factors that determine the neuronal types resulting from astrocyte transdifferentiation, AAV-mediated astrocyte-to-neuron conversion in vivo may offer a promising approach for specific neuronal replacement in patients with brain injury or neuronal degeneration (Jopling et al., 2011).

Most recently, several studies reported that non-neuronal cells, including reactive astrocytes, could be converted into neurons or neuroblasts in the adult brain or spinal cord (Grande et al., 2013; Niu et al., 2013; Torper et al., 2013; Guo et al., 2014; Su et al., 2014), although differentiated cells may be refractory to fate reprogramming compared with neural progenitors (Ohori et al., 2006; Su et al., 2014). Although the prospect of reprogramming astrocytes into neurons in vivo is exciting, many important issues remain to be addressed (Arlotta and Berninger, 2014). It will be of great importance to study whether different neuronal subtypes could be induced efficiently in vivo and whether the iN cells can integrate into functional circuits and rescue behavioral deficits.

\section{References}

Ang CE, Wernig M (2014) Induced neuronal reprogramming. J Comp Neurol 522:2877-2886. CrossRef Medline

Arlotta P, Berninger B (2014) Brains in metamorphosis: reprogramming cell identity within the central nervous system. Curr Opin Neurobiol 27:208-214. CrossRef Medline 
Atasoy D, Aponte Y, Su HH, Sternson SM (2008) A FLEX switch targets Channelrhodopsin-2 to multiple cell types for imaging and long-range circuit mapping. J Neurosci 28:7025-7030. CrossRef Medline

Berninger B, Guillemot F, Götz M (2007a) Directing neurotransmitter identity of neurones derived from expanded adult neural stem cells. Eur J Neurosci 25:2581-2590. CrossRef Medline

Berninger B, Costa MR, Koch U, Schroeder T, Sutor B, Grothe B, Götz M (2007b) Functional properties of neurons derived from in vitro reprogrammed postnatal astroglia. J Neurosci 27:8654-8664. CrossRef Medline

Bertrand N, Castro DS, Guillemot F (2002) Proneural genes and the specification of neural cell types. Nat Rev Neurosci 3:517-530. CrossRef Medline

Buffo A, Vosko MR, Ertürk D, Hamann GF, Jucker M, Rowitch D, Götz M (2005) Expression pattern of the transcription factor Olig2 in response to brain injuries: implications for neuronal repair. Proc Natl Acad Sci U S A 102:18183-18188. CrossRef Medline

Cahoy JD, Emery B, Kaushal A, Foo LC, Zamanian JL, Christopherson KS, Xing Y, Lubischer JL, Krieg PA, Krupenko SA, Thompson WJ, Barres BA (2008) A transcriptome database for astrocytes, neurons, and oligodendrocytes: a new resource for understanding brain development and function. J Neurosci 28:264-278. CrossRef Medline

Caiazzo M, Dell'Anno MT, Dvoretskova E, Lazarevic D, Taverna S, Leo D, Sotnikova TD, Menegon A, Roncaglia P, Colciago G, Russo G, Carninci P, Pezzoli G, Gainetdinov RR, Gustincich S, Dityatev A, Broccoli V (2011) Direct generation of functional dopaminergic neurons from mouse and human fibroblasts. Nature 476:224-227. CrossRef Medline

Casarosa S, Fode C, Guillemot F (1999) Mash1 regulates neurogenesis in the ventral telencephalon. Development 126:525-534. Medline

Chanda S, Ang CE, Davila J, Pak C, Mall M, Lee QY, Ahlenius H, Jung SW, Südhof TC, Wernig M (2014) Generation of induced neuronal cells by the single reprogramming factor ASCL1. Stem Cell Reports 3:282-296. CrossRef Medline

Ganat YM, Silbereis J, Cave C, Ngu H, Anderson GM, Ohkubo Y, Ment LR, Vaccarino FM (2006) Early postnatal astroglial cells produce multilineage precursors and neural stem cells in vivo. J Neurosci 26:8609-8621. CrossRef Medline

Gong S, Zheng C, Doughty ML, Losos K, Didkovsky N, Schambra UB, Nowak NJ, Joyner A, Leblanc G, Hatten ME, Heintz N (2003) A gene expression atlas of the central nervous system based on bacterial artificial chromosomes. Nature 425:917-925. CrossRef Medline

Gong S, Doughty M, Harbaugh CR, Cummins A, Hatten ME, Heintz N, Gerfen CR (2007) Targeting Cre recombinase to specific neuron populations with bacterial artificial chromosome constructs. J Neurosci 27: 9817-9823. CrossRef Medline

Grande A, Sumiyoshi K, López-Juárez A, Howard J, Sakthivel B, Aronow B, Campbell K, Nakafuku M (2013) Environmental impact on direct neuronal reprogramming in vivo in the adult brain. Nat Commun 4:2373. CrossRef Medline

Grieger JC, Choi VW, Samulski RJ (2006) Production and characterization of adeno-associated viral vectors. Nat Protoc 1:1412-1428. CrossRef Medline

Guimera J, Weisenhorn DV, Wurst W (2006) Megane/Heslike is required for normal GABAergic differentiation in the mouse superior colliculus. Development 133:3847-3857. CrossRef Medline

Guo Z, Zhao C, Huang M, Huang T, Fan M, Xie Z, Chen Y, Zhao X, Xia G, Geng J, Cheng L (2012) Tlx1/3 and Ptfla control the expression of distinct sets of transmitter and peptide receptor genes in the developing dorsal spinal cord. J Neurosci 32:8509-8520. CrossRef Medline

Guo Z, Zhang L, Wu Z, Chen Y, Wang F, Chen G (2014) In Vivo direct reprogramming of reactive glial cells into functional neurons after brain injury and in an Alzheimer's disease model. Cell Stem Cell 14:188-202. CrossRef Medline

Gurdon JB (2006) From nuclear transfer to nuclear reprogramming: the reversal of cell differentiation. Annu Rev Cell Dev Biol 22:1-22. CrossRef Medline

Heinrich C, Blum R, Gascón S, Masserdotti G, Tripathi P, Sánchez R, Tiedt S, Schroeder T, Götz M, Berninger B (2010) Directing astroglia from the cerebral cortex into subtype specific functional neurons. PLoS Biol 8:e1000373. CrossRef Medline

Hewett JA (2009) Determinants of regional and local diversity within the astroglial lineage of the normal central nervous system. J Neurochem 110:1717-1736. CrossRef Medline

Holmberg J, Perlmann T (2012) Maintaining differentiated cellular identity. Nat Rev Genet 13:429-439. CrossRef Medline

Horton S, Meredith A, Richardson JA, Johnson JE (1999) Correct coordination of neuronal differentiation events in ventral forebrain requires the bHLH factor MASH1. Mol Cell Neurosci 14:355-369. CrossRef Medline

Huang T, Liu Y, Huang M, Zhao X, Cheng L (2010) Wnt1-cre-mediated conditional loss of Dicer results in malformation of the midbrain and cerebellum and failure of neural crest and dopaminergic differentiation in mice. J Mol Cell Biol 2:152-163. CrossRef Medline

Jessberger S, Toni N, Clemenson GD Jr, Ray J, Gage FH (2008) Directed differentiation of hippocampal stem/progenitor cells in the adult brain. Nat Neurosci 11:888-893. CrossRef Medline

Jopling C, Boue S, Izpisua Belmonte JC (2011) Dedifferentiation, transdifferentiation and reprogramming: three routes to regeneration. Nat Rev Mol Cell Biol 12:79-89. CrossRef Medline

Kala K, Haugas M, Lilleväli K, Guimera J, Wurst W, Salminen M, Partanen J (2009) Gata2 is a tissue-specific post-mitotic selector gene for midbrain GABAergic neurons. Development 136:253-262. CrossRef Medline

Kalderon D, Roberts BL, Richardson WD, Smith AE (1984) A short amino acid sequence able to specify nuclear location. Cell 39:499-509. CrossRef Medline

Kaneko K, Tamamaki N, Owada H, Kakizaki T, Kume N, Totsuka M, Yamamoto T, Yawo H, Yagi T, Obata K, Yanagawa Y (2008) Noradrenergic excitation of a subpopulation of GABAergic cells in the basolateral amygdala via both activation of nonselective cationic conductance and suppression of resting $\mathrm{K}+$ conductance: a study using glutamate decarboxylase 67 -green fluorescent protein knock-in mice. Neuroscience 157: 781-797. CrossRef Medline

Kang SH, Fukaya M, Yang JK, Rothstein JD, Bergles DE (2010) NG2+ CNS glial progenitors remain committed to the oligodendrocyte lineage in postnatal life and following neurodegeneration. Neuron 68:668-681. CrossRef Medline

Karow M, Sánchez R, Schichor C, Masserdotti G, Ortega F, Heinrich C, Gascón S, Khan MA, Lie DC, Dellavalle A, Cossu G, Goldbrunner R, Götz M, Berninger B (2012) Reprogramming of pericyte-derived cells of the adult human brain into induced neuronal cells. Cell Stem Cell 11:471476. CrossRef Medline

Kim J, Su SC, Wang H, Cheng AW, Cassady JP, Lodato MA, Lengner CJ, Chung CY, Dawlaty MM, Tsai LH, Jaenisch R (2011) Functional integration of dopaminergic neurons directly converted from mouse fibroblasts. Cell Stem Cell 9:413-419. CrossRef Medline

Lagace DC, Whitman MC, Noonan MA, Ables JL, DeCarolis NA, Arguello AA, Donovan MH, Fischer SJ, Farnbauch LA, Beech RD, DiLeone RJ, Greer CA, Mandyam CD, Eisch AJ (2007) Dynamic contribution of nestin-expressing stem cells to adult neurogenesis. J Neurosci 27:1262312629. CrossRef Medline

Laywell ED, Rakic P, Kukekov VG, Holland EC, Steindler DA (2000) Identification of a multipotent astrocytic stem cell in the immature and adult mouse brain. Proc Natl Acad Sci U S A 97:13883-13888. CrossRef Medline

Lentz TB, Gray SJ, Samulski RJ (2012) Viral vectors for gene delivery to the central nervous system. Neurobiol Dis 48:179-188. CrossRef Medline

Lu JT, Li CY, Zhao JP, Poo MM, Zhang XH (2007) Spike-timing-dependent plasticity of neocortical excitatory synapses on inhibitory interneurons depends on target cell type. J Neurosci 27:9711-9720. CrossRef Medline

Madisen L, Zwingman TA, Sunkin SM, Oh SW, Zariwala HA, Gu H, Ng LL, Palmiter RD, Hawrylycz MJ, Jones AR, Lein ES, Zeng H (2010) A robust and high-throughput Cre reporting and characterization system for the whole mouse brain. Nat Neurosci 13:133-140. CrossRef Medline

Markram H, Toledo-Rodriguez M, Wang Y, Gupta A, Silberberg G, Wu C (2004) Interneurons of the neocortical inhibitory system. Nat Rev Neurosci 5:793-807. CrossRef Medline

Marro S, Pang ZP, Yang N, Tsai MC, Qu K, Chang HY, Südhof TC, Wernig M (2011) Direct lineage conversion of terminally differentiated hepatocytes to functional neurons. Cell Stem Cell 9:374-382. CrossRef Medline

McCarthy KD, de Vellis J (1980) Preparation of separate astroglial and oligodendroglial cell cultures from rat cerebral tissue. J Cell Biol 85:890-902. CrossRef Medline

Mirakhori F, Zeynali B, Salekdeh GH, Baharvand H (2014) Induced neural 
lineage cells as repair kits: so close, yet so far away. J Cell Physiol 229:728 742. CrossRef Medline

Naldini L, Blömer U, Gage FH, Trono D, Verma IM (1996) Efficient transfer, integration, and sustained long-term expression of the transgene in adult rat brains injected with a lentiviral vector. Proc Natl Acad Sci U S A 93:11382-11388. CrossRef Medline

Niu W, Zang T, Zou Y, Fang S, Smith DK, Bachoo R, Zhang CL (2013) In vivo reprogramming of astrocytes to neuroblasts in the adult brain. Nat Cell Biol 15:1164-1175. CrossRef Medline

Ohori Y, Yamamoto S, Nagao M, Sugimori M, Yamamoto N, Nakamura K, Nakafuku M (2006) Growth factor treatment and genetic manipulation stimulate neurogenesis and oligodendrogenesis by endogenous neural progenitors in the injured adult spinal cord. J Neurosci 26:11948-11960. CrossRef Medline

Parras CM, Schuurmans C, Scardigli R, Kim J, Anderson DJ, Guillemot F (2002) Divergent functions of the proneural genes Mash1 and Ngn2 in the specification of neuronal subtype identity. Genes Dev 16:324-338. CrossRef Medline

Paxinos G, Franklin KBJ (2001) The mouse brain in stereotaxic coordinates. San Diego: Academic.

Peltopuro P, Kala K, Partanen J (2010) Distinct requirements for Ascl1 in subpopulations of midbrain GABAergic neurons. Dev Biol 343:63-70. CrossRef Medline

Pevny L, Rao MS (2003) The stem-cell menagerie. Trends Neurosci 26:351359. CrossRef Medline

Pfisterer U, Kirkeby A, Torper O, Wood J, Nelander J, Dufour A, Björklund A, Lindvall O, Jakobsson J, Parmar M (2011) Direct conversion of human fibroblasts to dopaminergic neurons. Proc Natl Acad Sci U S A 108: 10343-10348. CrossRef Medline

Son EY, Ichida JK, Wainger BJ, Toma JS, Rafuse VF, Woolf CJ, Eggan K (2011) Conversion of mouse and human fibroblasts into functional spinal motor neurons. Cell Stem Cell 9:205-218. CrossRef Medline

Su M, Hu H, Lee Y, d'Azzo A, Messing A, Brenner M (2004) Expression specificity of GFAP transgenes. Neurochem Res 29:2075-2093. CrossRef Medline

Su Z, Niu W, Liu ML, Zou Y, Zhang CL (2014) In vivo conversion of astro- cytes to neurons in the injured adult spinal cord. Nat Commun 5:3338. CrossRef Medline

Takahashi K, Yamanaka S (2006) Induction of pluripotent stem cells from mouse embryonic and adult fibroblast cultures by defined factors. Cell 126:663-676. CrossRef Medline

Tiscornia G, Singer O, Verma IM (2006) Production and purification of lentiviral vectors. Nat Protoc 1:241-245. CrossRef Medline

Torper O, Pfisterer U, Wolf DA, Pereira M, Lau S, Jakobsson J, Björklund A, Grealish S, Parmar M (2013) Generation of induced neurons via direct conversion in vivo. Proc Natl Acad Sci U S A 110:7038-7043. CrossRef Medline

Vierbuchen T, Ostermeier A, Pang ZP, Kokubu Y, Südhof TC, Wernig M (2010) Direct conversion of fibroblasts to functional neurons by defined factors. Nature 463:1035-1041. CrossRef Medline

Volterra A, Meldolesi J (2005) Astrocytes, from brain glue to communication elements: the revolution continues. Nat Rev Neurosci 6:626-640. CrossRef Medline

Wapinski OL, Vierbuchen T, Qu K, Lee QY, Chanda S, Fuentes DR, Giresi PG, Ng YH, Marro S, Neff NF, Drechsel D, Martynoga B, Castro DS, Webb AE, Südhof TC, Brunet A, Guillemot F, Chang HY, Wernig M (2013) Hierarchical mechanisms for direct reprogramming of fibroblasts to neurons. Cell 155:621-635. CrossRef Medline

Yang N, Ng YH, Pang ZP, Südhof TC, Wernig M (2011) Induced neuronal cells: how to make and define a neuron. Cell Stem Cell 9:517-525. CrossRef Medline

Zhang SY, Xu M, Miao QL, Poo MM, Zhang XH (2009) Endocannabinoiddependent homeostatic regulation of inhibitory synapses by miniature excitatory synaptic activities. J Neurosci 29:13222-13231. CrossRef Medline

Zhang Y, Barres BA (2010) Astrocyte heterogeneity: an underappreciated topic in neurobiology. Curr Opin Neurobiol 20:588-594. CrossRef Medline

Zhuo L, Sun B, Zhang CL, Fine A, Chiu SY, Messing A (1997) Live astrocytes visualized by green fluorescent protein in transgenic mice. Dev Biol 187: 36-42. CrossRef Medline 